\title{
Aplicación de los estándares interamericanos sobre expulsión de extranjeros en el sistema jurídico chileno ${ }^{1}$
}

\author{
Application of the Inter-American standards on the \\ expulsion of aliens in the Chilean juridical system
}

\section{Regina Ingrid DíAz Tolosa ${ }^{2}$ \\ Universidad Autónoma de Chile \\ ridiaz@uc.cl}

\begin{abstract}
Resumen: La autora sostiene que, siendo el Estado de Chile miembro integrante del sistema interamericano de protección de los derechos humanos, y los tribunales de justicia, órganos del Estado obligados a respetar y promover los derechos humanos, debiese existir una aplicación de los estándares interamericanos protectores de los derechos de las personas migrantes en la revisión judicial de órdenes de expulsión. Luego, el artículo analiza la jurisprudencia de los tribunales superiores de justicia chilenos durante los últimos 10 años para verificar si se ha efectuado esta implementación.
\end{abstract}

1 Este artículo forma parte de la investigación financiada por la Comisión Nacional de Ciencia y Tecnología, proyecto Fondecyt Regular 2018-2020, n 1181194, titulado "Aporte de los tribunales de justicia a la protección efectiva de los derechos de las personas migrantes".

2 Doctora en Derecho por la Pontificia Universidad Católica de Chile. Directora de Carrera de Derecho Sede Santiago, Universidad Autónoma de Chile, Chile. 
Palabras clave: Migrantes, expulsiones, estándar interamericano, aplicación del derecho internacional en el derecho interno.

\begin{abstract}
The author maintains that, being the State of Chile a member of the inter-American system for the protection of human rights, and the courts of justice, organs of the State obliged to respect and promote the human rights, there should be an application of the inter-American standards that protect the rights of migrants in the judicial review of expulsion orders. Then, the article analyzes the jurisprudence of the Chilean superior courts of justice during the last 10 years to verify if this implementation has been carried out.
\end{abstract}

Keywords: Migrants, expulsions, inter-American standard, application of international law in domestic law.

\title{
1. Introducción
}

El sistema interamericano de protección de los derechos humanos inicia con la creación de la Organización de Estados Americanos (en adelante OEA) en 1948, en el período inmediatamente posterior a la Segunda Guerra Mundial, unido al fenómeno del panamericanismo, considerando al resguardo de los derechos humanos como un fundamento para garantizar la paz en el continente. ${ }^{3}$ En un principio era un sistema muy básico ${ }^{4}$, pero hoy tras más de 60 años de permanencia, ha desarrollado y fortalecido los mecanismos de protección de los derechos humanos, siendo un referente relevante en la materia para los Estados de la región, y más aún para aquellos que lo integran formalmente.

Chile forma parte de este sistema, no solo como miembro activo de la OEA, sino también por haber ratificado y puesto en vigencia la Convención Americana sobre Derechos Humanos de 1969 (en adelante CADH) y haber aceptado la jurisdicción de la Corte Interamericana de Derechos

3 Cfr. Resolución IX de la Conferencia Interamericana sobre Problemas de la Guerra y la Paz (Chapultepec, 1945) y en el Tratado Interamericano de Asistencia Recíproca (1947).

4 Por ejemplo, entre 1948 y 1969 el proceso codificador fue prácticamente inexistente; la Comisión Interamericana, de acuerdo con su Estatuto original de 1960, sólo promovía el estudio de los derechos humanos en América y hacía recomendaciones a los Estados miembros. DíAz (2015), p. 238, n. 79. 
Humanos (en adelante CtIDH), por lo que ha dado su consentimiento expreso en aras de comprometer la implementación de mecanismos de salvaguarda de estos derechos. Por cierto, el sistema interamericano de protección de los derechos humanos es coadyuvante y complementario del derecho interno. ${ }^{5}$

En este contexto, corresponde a los tribunales de justicia chilenos, en la revisión judicial de órdenes de expulsión de extranjeros ${ }^{6}$, dar aplicación a los estándares interamericanos protectores de los derechos de las personas migrantes, pues existe un deber general de respeto y garantía de los derechos humanos, el cual se proyecta a todos los órganos del Estado y se manifiesta en un deber de garantizar la protección eficaz (effet utile) de estos, lo cual implica no dictar resoluciones manifiestamente incompatibles con las obligaciones internacionales que ha asumido el Estado e intentar armonizar en el mayor grado posible las normas internacionales y las internas con una interpretación sistemática y finalista. ${ }^{7}$ En efecto, la Constitución, en su artículo $5^{\circ}$, declara el deber de respeto y de promoción de los derechos de la persona humana impuesta a los órganos del Estado. Entre esos órganos, corresponde también al Poder Judicial respetar y promover los derechos humanos garantidos en el sistema internacional. ${ }^{8}$

Luego, el objetivo de este artículo es verificar si los jueces chilenos han logrado durante los últimos 10 años dar una protección más efectiva a los derechos de las personas migrantes en casos de expulsión, a través de la aplicación de la CADH y la interpretación que ha realizado a su respecto la CtIDH. Esta Corte ha conocido de diversos casos contenciosos

5 Cfr. Díaz (2015), p. 246; DíAz (2016a), pp. 181 y 182.

6 Es necesario precisar que el vocablo "extranjeros" se utiliza en referencia a los no nacionales, mientras que el término "migrantes" refiere al extranjero que ingresa a un Estado distinto del de su origen para establecerse en él con ánimo de permanencia temporal o definitiva. Así, entre las nociones "extranjero" y "migrante" existe una relación género-especie, siendo el primero un concepto más amplio. Ello es patente respecto de los "turistas", aquellos extranjeros -o no nacionales- que ingresan al país con fines de recreo, deportivos, de salud, de estudios, de gestión de negocios, familiares, religiosos u otros similares, pero sin propósito de inmigración, residencia o desarrollo de actividades remuneradas.

7 Cfr. NASH (2013), pp. 169 y 170.

8 NASH y NúÑEz (2017a), pp. 16 y 17, NúÑEz (2015), p. 164. 
y solicitudes de opinión consultiva relativas a la protección de derechos de las personas migrantes, los cuales es necesario considerar dada su relevancia, pues los demás Estados miembros del sistema interamericano de protección de los derechos humanos, aunque no hayan sido parte en los procesos, pueden seguir estas decisiones, en cuanto interpretan las disposiciones de la $\mathrm{CADH}$ aplicables para una efectiva protección de las personas migrantes. ${ }^{9}$

Si bien en Chile no existe norma legal o constitucional que otorgue expresamente a la jurisprudencia interamericana un efecto vinculante amplio $^{10}$, los tribunales nacionales debieran seguir la jurisprudencia de los órganos jurisdiccionales internacionales, sin perjuicio del margen de discreción limitado del que disponen ${ }^{11}$, en cuanto han de realizar una interpretación armónica del derecho interno con las obligaciones provenientes del derecho internacional. ${ }^{12}$

9 GALDÁmEZ (2014), p. 336, afirma que el seguimiento de la doctrina de la CtIDH "no es una cuestión que los Estados puedan libremente decidir. Se trata de una obligación oponible a todo Estado que haya reconocido su jurisdicción. Según esta tesis, las opiniones de la Corte, sea el Estado directamente condenado o no, deben ser seguidas por los tribunales nacionales y los poderes del Estado para con ello garantizar el respeto y cumplimiento de los compromisos contenidos en la Convención Americana".

Por su parte, HITTERs (2013), p. 707, destaca -parafraseando CtIDH, Caso Gelman, Supervisión de Cumplimiento de Sentencia, 20 de marzo de 2013, pár. 59- que si "el Estado no ha sido parte en el proceso internacional donde se fijó la jurisprudencia. En tal hipótesis por el solo hecho de ser Parte en la Convención, la conducta de sus autoridades públicas y de la totalidad de sus órganos incluidos las instancias democráticas, están obligadas por el Tratado debiéndose acatar el mismo y considerar los precedentes y lineamientos judiciales del Tribunal Interamericano". En el mismo sentido, Henríquez (2018), p. 346; García Jaramillo (2016), pp. 144 y 145; García Ramírez (2016), p. 174; FerRer (2016), p. 340; FERRER (2011), pp. 561 y 568.

10 Cfr. Henriquez (2018), p. 353; Alfonso (2010), pp. 64 y 70.

11 Contreras (2015), p. 426, afirma que los "Estados poseen un margen de discreción en determinación de las garantías, restricciones y cumplimiento de las obligaciones internacionales de derechos humanos". Este margen se ve reducido por el control de convencionalidad, el cual "impone nuevos deberes a los órganos estatales internos".

12 Cfr. Henríquez (2018), pp. 343 y 352; García Jaramillo (2016), pp. 135 y 136.

Tal como destaca STEINER y URIBE (2014) p. 10, los derechos humanos "pueden estar reconocidos expresamente en la Constitución, y también establecidos en los tratados universales, así como los regionales del sistema interamericano; el derecho tendrá entonces una triple protección: a nivel doméstico, internacional y regional. En otras palabras, el operador jurídico tendrá frente a sí, un cúmulo de normas de origen nacional e internacional que apuntan hacia una misma dirección, la pregunta fundamental es ¿cómo habrá de interpretarse ese derecho?, la respuesta es de la manera en la que se otorgue la mayor protección tomando en cuenta las circunstancias del 
Al respecto, se ha de considerar que las decisiones de los tribunales internacionales han ejercido considerable influencia en el desarrollo del derecho internacional, y tienden a ser invocadas como testimonio autorizado de sus reglas e inspiran decisiones judiciales posteriores. Así, las sentencias de los tribunales internacionales trascienden sus efectos relativos formales, pues los criterios en ellas vertidos constituyen una explicación directa y última, acerca de las disposiciones del derecho internacional, conformando así, la norma y su interpretación, el estándar normativo cuyo cumplimiento puede ser exigido y que debe ser observado por los Estados. ${ }^{13}$

Los resultados de la investigación se presentan en tres apartados. Primero, se sistematiza el contenido del estándar interamericano aplicable en materia de expulsión de extranjeros (sección 1). Para luego examinar si se ha dado una debida implementación de este estándar en el sistema jurídico chileno, tanto por parte de legislador (sección 2) como del poder judicial (sección 3).

\section{El Estándar interamericano aplicable en procedimientos de expulsión de extranjeros}

Antes de precisar y sistematizar el contenido del estándar interamericano de protección de las personas migrantes es necesario destacar que la fuerza del concepto de "estándares jurídicos internacionales" ha sido disipada debido a la amplitud de su uso y la imprecisión de su contenido. En tal sentido, concordamos en cuanto a "la importancia de saber qué es lo que estamos invocando como imperativo internacional y cuál es su implicancia en el ámbito nacional". ${ }^{14}$

Así, en consideración de la problemática respecto de las nociones "es-

caso concreto".

13 Cfr. SagüÉs (2003), p. 214; Benadava (2004), p. 32.

STEINER y URIBE (2014), p. 10, destacan que una fórmula efectiva para lograr la armonización entre el derecho nacional y el internacional es a través de la cláusula de interpretación conforme, técnica hermenéutica por medio de la cual los tratados internacionales son armonizados con los valores, principios y normas contenidos en otras resoluciones y fuentes internacionales, para lograr su mayor eficacia y protección.

14 Molina (2018), pp. 236 y 237. 
tándar", "estándar jurídico" o "estándar internacional"15, concebimos al concepto de "estándar internacional" como aquél que refiere a una serie de fuentes del derecho internacional, incluyendo al soft law aplicable en materia de derecho migratorio, como por ejemplo, informes de los relatores especiales sobre migración, resoluciones de la Asamblea General de las Naciones Unidas, observaciones generales de los comités de las Naciones Unidas que supervigilan el cumplimiento de los tratados internacionales sobre derechos humanos, interpretaciones de cortes internacionales contenidas en su jurisprudencia contenciosa o consultiva sobre derechos reconocidos en tratados internacionales, todos los cuales sirven para delimitar el contenido y alcance de tales derechos. En otras palabras, bajo el concepto de "estándar internacional" incluimos en el mandato de las disposiciones de los tratados internacionales sobre derechos humanos -fuentes del derecho internacional convencional con fuerza vinculante en los Estados parte que los han ratificado y puesto en vigencia interna-, el cúmulo de fuentes complementarias que coadyuvan a su interpretación para una correcta determinación del contenido y alcance de la norma, lo cual facilita una posterior implementación a nivel

15 Molina (2018), p. 239 refiere al concepto de "estándar" desarrollado en el marco del trabajo de la ISO (International Organization for Standarization): "Los estándares son construcciones culturales, efectuadas por quienes poseen autoridad ética, técnica, teórica o científica, según el caso, de público conocimiento que nos dan confianza en nuestro accionar, pues nos sirven de guía y referencia, y a posteriori permite controlar lo producido para realizar sobre ello un juicio de valor"; ídem., p. 242, al concepto de "estándar jurídico" dado por la Comisión Interamericana de Derechos Humanos: "conjunto de decisiones judiciales, informes temáticos y de país, y otras recomendaciones adoptadas por la Comisión Interamericana de Derechos Humanos. El término "estándares jurídicos" asimismo se refiere a los tratados regionales de derechos humanos que gobiernan el sistema interamericano (...) El concepto igualmente se refiere a las sentencias y opiniones consultivas emitidas por la Corte Interamericana de Derechos Humanos". Por su parte, ContRERAs (2017) p. 147, indica que la CtIDH en serie A $n^{\circ} 16,1$ de octubre de 1999, utiliza la expresión "corpus juris del derecho internacional de los derechos humanos" como sinónimo de "estándar de derecho internacional", al tratarse de una referencia general al conjunto de obligaciones internacionales que se derivan de distintas fuentes formales del derecho internacional ("conjunto de instrumentos internacionales de contenido y efectos jurídicos variados (tratados, convenios, resoluciones y declaraciones)), cuya función es interpretativa, en cuanto sirve para "fijar el contenido y alcance" de la CADH"). Luego, ídem., p. 148 refiere a la CtIDH, serie A n 18 , 17 de septiembre 2003, para enfatizar que "el corpus juris está formado por distintos instrumentos internacionales, tanto de hard law (tratados/convenciones), como de soft law (resoluciones/ declaraciones)". 
interno. En consecuencia, específicamente en este artículo utilizamos el concepto "estándar interamericano" para aludir a la interpretación que ha realizado la CtIDH respecto de la $\mathrm{CADH}$ en materia de migración. ${ }^{16}$

A continuación, revisamos el contenido del estándar interamericano en materias de deportación a través de la sistematización de las argumentaciones de la CtIDH en interpretación y aplicación de los artículos 7, 8 y 22 de la CADH sobre derecho de circulación y de residencia en relación con el derecho a la libertad personal y a las garantías judiciales. Asimismo, respecto del artículo 17.1 de la $\mathrm{CADH}$ sobre protección a la familia, en cuanto además del derecho a un debido proceso y otras salvaguardas procesales en casos de expulsión ${ }^{17}$, el derecho a la reunificación fami$\operatorname{liar}^{18}$ se ha configurado como un elemento significativo para ponderar si la medida de expulsión es razonable, es decir, necesaria y proporcional al fin que persigue.

\subsection{Garantías mínimas procesales aplicables en casos de expulsión de extranjeros}

La Corte enfatiza la existencia de un mínimo de garantías procesales que deben respetarse en caso de expulsiones de extranjeros, sea que se encuentren lícitamente en el territorio de un Estado parte, o bien, si se cuestiona la licitud de su entrada o permanencia. ${ }^{19}$ El debido proceso

16 Respecto de su fuerza vinculante, remitirse a la sección 3 sobre la aplicación del estándar interamericano de protección de las personas migrantes en casos de expulsión por los tribunales superiores de justicia chilenos, pues antes de presentar el análisis, se enfatizan los efectos en las jurisdicciones nacionales de la jurisprudencia de la CtIDH como intérprete auténtica de la CADH.

17 El derecho a expulsar a los extranjeros es un derecho inherente del Estado, que se desprende de su soberanía, pero sujeto a la prohibición de la arbitrariedad, el abuso del derecho y la denegación de justicia. Cfr. NACIONES UNIDAS (2014), pp. 25 y 26, 29 y 30; SHAW (2008), p. 826; HERDEGEN (2005), pp. 210 y 211.

18 La disposición solo consagra a la familia como elemento natural y fundamental de la sociedad sin reconocer expresamente y de manera autónoma el derecho a la reagrupación familiar Por tanto, el derecho a la protección de la familia no garantiza un derecho a favor de un extranjero a entrar o residir en el territorio de un país determinado, sin embargo, se ha recomendado evitar la expulsión de los no ciudadanos, especialmente de los residentes de larga data, que pueda tener como resultado una interferencia desproporcionada en el derecho a la vida familiar. Cfr. Comité para la Eliminación de la Discriminación Racial Recomendación general $N^{\circ} X X X$ sobre la discriminación contra los no ciudadanos, 2005, pár. 28; SÁNCHEZ-RODAs (2006), p. 298.

$19 \mathrm{Si}$ bien el artículo 22.6 de la CADH establece que "[e]l extranjero que se halle legalmente 
legal es un derecho que debe ser garantizado a toda persona, independientemente de su estatus migratorio. Esto implica que el Estado debe garantizar que toda persona extranjera, aun cuando fuere un migrante en situación irregular, tenga la posibilidad de hacer valer sus derechos y defender sus intereses en forma efectiva y en condiciones de igualdad procesal con otros justiciables. ${ }^{20}$

Por tanto, se debe cumplir al menos con las siguientes garantías ${ }^{21}$ :

a) la medida de expulsión solo podrá efectuarse tras una decisión adoptada conforme a la ley, ${ }^{22}$

en el territorio de un Estado parte en la presente Convención, sólo podrá ser expulsado de él en cumplimiento de una decisión adoptada conforme a la ley", la CtIDH ha interpretado que la disposición también es aplicable si se encuentran en situación migratoria irregular, sea porque han ingresado al país ilegalmente o permanecen en él más allá del tiempo permitido, esto porque ello forma para de las garantías que componen el debido proceso del art. 8 de la CADH, por tanto se garantizan a toda persona. (cfr. CtIDH: serie A $n^{\circ} 16,1$ de octubre de 1999, párs. 117 y 119; serie $A n^{\circ} 18,17$ de septiembre de 2003, párs. 121 y 122; serie $C n^{\circ} 282,28$ de agosto de 2014, pár. 351 , serie $C n^{\circ} 251,24$ de octubre 2012, párs. 154, 158-160; serie $C n^{\circ} 218,23$ noviembre 2010, pár. 100; serie $A \mathrm{n}^{\circ} 18,17$ de septiembre 2003, pár. 119).

20 CtIDH: serie $C \mathrm{n}^{\circ} 282,28$ de agosto de 2014, pár. 351; serie $C \mathrm{n}^{\circ} 251,24$ de octubre 2012 , párs. 158 y 159; serie $\mathrm{C} \mathrm{n}^{\circ} 218,23$ noviembre 2010, pár. 143.

$21 \mathrm{CtIDH}$ : serie $\mathrm{C} \mathrm{n}^{\circ} 282,28$ de agosto de 2014, párs. 352-356; serie $\mathrm{C} \mathrm{n}^{\circ} 251,24$ de octubre 2012, párs. 160, 162, 163 y 174.

22 De acuerdo con el artículo 22.3 de la $\mathrm{CADH}$, el derecho de circulación y de residencia "no puede ser restringido sino en virtud de una ley, en la medida indispensable en una sociedad democrática, para prevenir infracciones penales o para proteger la seguridad nacional, la seguridad o el orden públicos, la moral o la salud públicas o los derechos y libertades de los demás".

UPRIMNY y SÁNCHEZ (2014), pp. 536-538, concluyen que "la legitimidad de una restricción al derecho a la libertad de circulación y de residencia, depende del cumplimiento de cuatro condiciones, a saber, i) la legalidad de la medida, ii) la legitimidad de los propósitos buscados, iii) la necesidad y proporcionalidad y iv) el respeto del contenido esencial del derecho". Respecto de la legalidad de la medida, destacan, que "[e]ste requisito formal es en sí mismo de gran importancia pues ampara a los ciudadanos contra limitaciones a sus derechos humanos por parte de autoridades administrativas. Debe ser la ley, expresión del principio democrático y garantía de seguridad jurídica, la que defina con claridad los casos en los cuales cabe restringir la libertad de circular por un territorio y escoger libremente el lugar de residencia". Luego, la restricción no solo debe encontrarse establecida en la ley, sino además debe satisfacer ciertos requisitos sustantivos, para ser legítimas: "no deben sólo perseguir los propósitos autorizados por la Convención -la protección de seguridad nacional, el orden público, la salud o la moral públicas o los derechos y libertades de terceros, sino además ser necesarias en una sociedad democrática para alcanzar tales propósitos, lo cual remite a un análisis de proporcionalidad", entendido como "un análisis detallado y estricto para determinar que existe una relación de adecuación entre la restricción y el fin perseguido y que no hay una medida menos gravosa para cumplir el propósito" es fundamental, ya que "si se invocan fines como la seguridad nacional o la moral pública, por su generalidad fácilmente pueden ser utilizados por algunos gobiernos para tratar de justificar violaciones a los derechos". 
b) la medida de expulsión debe notificarse para informar expresa y formalmente de los cargos en su contra y de los motivos de la expulsión. Esta notificación debe incluir información sobre sus derechos, tales como:

- la posibilidad de solicitar y recibir asistencia consular, asesoría legal gratuita y, de ser el caso, traducción o interpretación ${ }^{23}$;

- en caso de decisión desfavorable, la posibilidad de someter su caso a revisión ante la autoridad competente y presentarse ante ella para tal fin representado ${ }^{24}$.

Estas garantías mínimas (notificación de la medida, asistencia consular, asesoría jurídica gratuita, traducción o interpretación -de requerirse-, y revisión judicial), también son aplicables a la detención administrativa previa a la expulsión. Por su parte, se enfatiza que el extranjero tiene derecho a no ser privado de su libertad ilegal o arbitrariamente. ${ }^{25}$ Luego, se ha de considerar que, bajo el principio de tipicidad, se obliga a los Es-

Por tanto, como destaca Domínguez (2016), p. 197, "[e]n el examen de proporcionalidad debe establecerse (...) la existencia de razones suficientes y relevantes que justifican la medida de expulsión, sin que ninguna otra medida menos restrictiva sea realizable y ante la existencia de salvaguardas suficientes contra el abuso en el marco de un procedimiento justo".

$23 \mathrm{La}$ asistencia letrada debe ser ejercida por un profesional del derecho para poder satisfacer los requisitos de una defensa técnica a través de la cual se asesore a la persona sometida a proceso, inter alia, sobre la posibilidad de ejercer recursos contra actos que afecten sus derechos. La persona sometida a un proceso administrativo sancionatorio debe tener acceso a la defensa técnica desde ese mismo momento, ya que de lo contrario la asistencia legal carece de idoneidad por su falta de oportunidad. Asimismo, el Estado tiene la obligación de brindar asistencia legal gratuita a aquellas personas que carezcan de los medios económicos para poder asumir una defensa legal y así evitar la vulneración del derecho a las garantías del debido proceso. Cfr. CtIDH, serie $C \mathrm{n}^{\circ} 251,24$ de octubre 2012, pár. 164.

24 Los recursos de impugnación no solo deben existir formalmente en la legislación, sino que deben ser efectivos, esto es, cumplir con el objetivo de obtener una decisión sobre la legalidad de la medida de expulsión. Impedir a éste contar con la posibilidad de revisión de la medida es limitar severamente el derecho a la defensa, lo que ocasiona desequilibrio procesal y deja al individuo sin tutela frente al ejercicio del poder punitivo. Cfr. CtIDH: serie $\mathrm{C}^{\circ} 282,28$ de agosto de 2014 , pár. 356; serie $A n^{\circ} 18,17$ de septiembre de 2003, párs. 107 y 109.

$25 \mathrm{CADH}$, artículo 7: "Derecho a la Libertad Personal. 1. Toda persona tiene derecho a la libertad y a la seguridad personales. 2. Nadie puede ser privado de su libertad física, salvo por las causas y en las condiciones fijadas de antemano por las Constituciones Políticas de los Estados Partes o por las leyes dictadas conforme a ellas. 3. Nadie puede ser sometido a detención o encarcelamiento arbitrarios". 
tados a establecer, tan concretamente como sea posible y de antemano, las causas y condiciones de la privación de la libertad física. Por tanto, en aras de la seguridad jurídica es indispensable que la norma punitiva, sea penal o administrativa, exista y resulte conocida, o pueda serlo, antes de que ocurran la acción o la omisión que la contravienen y que se pretende sancionar. ${ }^{26}$ También, debe cumplirse con el principio de reserva legal, el cual impone que únicamente a través de una ley puede afectarse el derecho a la libertad personal. ${ }^{27}$

Por otra parte, nadie puede ser sometido a detención o encarcelamiento por causas y métodos que, aún calificados de legales, puedan reputarse como incompatibles con el respeto a los derechos fundamentales del individuo por ser, entre otras cosas, irrazonables, imprevisibles, o faltos de proporcionalidad. Por tanto, no se debe equiparar el concepto de "arbitrariedad" con el de "contrario a ley", sino que debe interpretarse de manera más amplia a fin de incluir elementos de incorrección, injusticia e imprevisibilidad. ${ }^{28}$ Así, en el caso de detenciones de migrantes para que no sean arbitrarias, han de basarse en una evaluación individualizada y dar cumplimiento a un interés legítimo estatal, v.g. asegurar la comparecencia de una persona al trámite de determinación de su estatus migratorio y posible deportación. ${ }^{29}$

\subsection{Prohibición de expulsiones colectivas de extranjeros y principio de no devolución}

En el contexto del desarrollo del derecho internacional para la protección de los derechos de las personas migrantes, se ha de considerar la plena observancia de la prohibición de expulsión colectiva de extranjeros

$26 \mathrm{CtIDH}$, serie $\mathrm{C} \mathrm{n}^{\circ} 218,23$ de noviembre de 2010, párs. 16 y 183.

27 Cfr. CtIDH, serie $C n^{\circ} 218,23$ de noviembre de 2010, pár. 167, refiere a la serie $A n^{\circ} 6,9$ de mayo de 1986. Luego, conforme al artículo 30 de la $\mathrm{CADH}$, esta ley es una norma jurídica de carácter general, ceñida al bien común, emanada de los órganos legislativos constitucionalmente previstos y democráticamente elegidos, y elaborada según el procedimiento establecido por las constituciones de los Estados para la formación de las leyes.

$28 \mathrm{CtIDH}$, serie $\mathrm{C} \mathrm{n}^{\circ} 282,28$ de agosto de 2014, pár. 364; serie $\mathrm{C} \mathrm{n}^{\circ} 251$, 24 de octubre 2012 , pár. 133.

29 Cfr. CtIDH, serie $C n^{\circ} 251$, pár. 134; serie $C n^{\circ} 218,23$ de noviembre de 2010 pár. 112. 
contenida en el artículo 22.9 de la $\mathrm{CADH}$, como límite reconocido de la aplicación de las políticas migratorias para garantizar el respeto de la dignidad humana, cualquiera que sea la condición jurídica del migrante. Luego, el criterio fundamental para determinar el carácter "colectivo" de una expulsión no es el número de extranjeros objeto de la decisión de expulsión, sino que la misma no se base en un análisis objetivo de las circunstancias individuales de cada extranjero. ${ }^{30}$

Así, se han de evaluar las circunstancias personales de cada sujeto, lo cual requiere, como mínimo, identificar a la persona y aclarar las circunstancias particulares de su situación migratoria. Asimismo, dicho procedimiento no debe discriminar debido a nacionalidad, color, raza, sexo, lengua, religión, opinión política, origen social u otro estatus, y ha de observar las señaladas garantías mínimas a observarse en procedimientos de expulsión. ${ }^{31}$

Por su parte, en cuanto al principio de no devolución, si bien, usualmente esta restricción de expulsión se estudia aparejada al derecho de asilo (artículo 22.7 de la CADH), está reconocido en el artículo 22.8 de forma amplia, es decir, respecto de cualquier persona extranjera, tenga o no la calidad de refugiado o asilado político, y sin importar su estatuto legal o condición migratoria en el país en que se encuentre. Así, la devolución a su Estado de origen será indebida si su vida, integridad o libertad pudiesen estar en riesgo de violación. En consecuencia, cuando un extranjero alegue ante un Estado un riesgo en caso de devolución, las autoridades competentes de ese Estado deberán, al menos, entrevistar a la persona y realizar una evaluación previa o preliminar, a efectos de determinar si existe o no ese riesgo en caso de expulsión. Esto implica respetar las garantías mínimas referidas, como parte de la debida oportunidad de exponer las razones que lo asistan en contra de su expulsión $y$, si se constata ese riesgo, no debería ser devuelto a su país de origen

30 Cfr. CtIDH: serie $\mathrm{C} \mathrm{n}^{\circ} 282,28$ de agosto de 2014, párs. 361-363; serie $\mathrm{C} \mathrm{n}^{\circ} 251,24$ de octubre 2012, párs. $154,155,168-174$.

31 Cfr. CtIDH, serie C n² 282, 28 de agosto de 2014, pár. 381. 
o donde exista el riesgo. ${ }^{32}$

\subsection{Principios del interés superior del niño y de la unidad familiar}

Los niños son sujetos de derechos y no objetos condicionados y limitados a los derechos de los padres. Por tanto, el Estado debe tomar medidas de protección orientadas en el principio del interés superior del niño, y en la necesidad de propiciar su desarrollo, con pleno aprovechamiento de sus potencialidades. ${ }^{33}$

En consecuencia, cualquier decisión de órgano judicial o administrativo que deba decidir acerca de la separación familiar, debido a la condición migratoria de uno a ambos progenitores debe contemplar las circunstancias particulares del caso concreto, garantizando así una decisión individual, y debe perseguir un fin legítimo, ser idónea, necesaria y proporcionada. En la consecución de ese fin, el Estado debe analizar las circunstancias particulares de cada caso, referidas $a^{34}$ :

a) la historia inmigratoria, el lapso temporal de la estadía y la extensión de los lazos del progenitor o de su familia con el país receptor;

b) la consideración sobre la nacionalidad, guarda y residencia de los hijos de la persona que se pretende deportar;

c) el alcance de la afectación que genera la ruptura familiar debido a la expulsión, incluyendo las personas con quiénes vive el niño, así como el tiempo que el niño ha permanecido en esta unidad familiar, y

d) el alcance de la perturbación en la vida diaria del niño si cambiara su situación familiar debido a una medida de expulsión de una persona a cargo del niño, de forma tal de ponderar estrictamente dichas circunstancias a la luz del interés superior del niño en relación con el interés público imperativo que su busca proteger.

$32 \mathrm{CtIDH}$, serie $\mathrm{C} \mathrm{n}^{\circ} 272,25$ de noviembre de 2013, párs. 135 y 136.

33 Cfr. CtIDH serie C n²82, 28 de agosto de 2014, párs. 344, 357; serie C n² 272, 25 de noviembre de 2013, párs. 226 y 228.

$34 \mathrm{CtIDH}$, serie $\mathrm{C} \mathrm{n}^{\circ}$ 282, 28 de agosto de 2014, párs. 414-417. 


\section{Adecuación de la normativa chilena al estándar interamericano de protección de los derechos de las personas migrantes en situación de expulsión}

El artículo $2^{\circ}$ de la CADH establece el deber de los Estados parte de adoptar disposiciones de derecho interno para hacer efectivos los derechos humanos en ella reconocidos. Esta disposición es un corolario de las normas de derecho internacional general reconocidas en la Convención de Viena sobre el Derecho de los Tratados (CVDT), referentes al principio pacta sunt servanda35 y a la relación entre el derecho interno y la observancia de los tratados. ${ }^{36}$ Se trata de una norma consuetudinaria reconocida con anterioridad a la codificación del Derecho de los Tratados por parte de la Corte Permanente de Justicia Internacional, la cual en fallos de principios del siglo XX, ya afirmaba que un Estado que ha contraído obligaciones internacionales está obligado a hacer en su derecho interno las modificaciones que sean necesarias para el cumplimiento de las mismas. ${ }^{37}$

Los Estados parte de la CADH para dar cumplimiento a este mandato de derecho internacional general y evitar una antinomia con el ordena-

35 Artículo 26 de la CVDT: "Todo tratado en vigor obliga a las partes y debe ser cumplido por ellas de buena fe". Se trata de un principio de origen consuetudinario que constituye un pilar fundamental del Derecho Internacional, considerada una regla de valor objetivo derivada de la idea misma de justicia; ni los acuerdos internacionales ni los derechos internos pueden condicionarlo, respecto a este principio sólo caben dos actitudes, respetarlo o violarlo. Cfr. WeHBERG (1959), pp.781-783; Sorensen (1973), pp. 158 y 159; Virally (1983), p. 130; Conforti (1995), p. 17; BenaDAVA (2004), p. 180; KotZUR (2009), pár. 7, 22-25; REINHOLD (2013), pp. 47-49.

36 Artículo 27 de la CVDT: "Una parte no podrá invocar las disposiciones de su derecho interno como justificación del incumplimiento de un tratado". También se trata de un principio consuetudinario existente en el Derecho Internacional con anterioridad a la entrada en vigor de la CVDT, prueba de ello es que con varias décadas de antelación la Corte Permanente de Justicia Internacional (en aelante CPJI) lo aludía en su jurisprudencia. Así, v.g., CPJI, Treatment of Polish Nationals and Other Persons of Polish Origin or Speech in the Danzig Territory, 1932, p. 24, señala que de acuerdo con principios generales aceptados, un Estado no puede aducir su propia Constitución como una manera de evadir obligaciones que le incumben por normas internacionales en vigor, y en CPJI, Case of the Free Zones of Upper Savoy and the District Of Gex, 1932, p. 12, un Estado no puede descansar en su propia legislación para limitar el alcance de sus obligaciones internacionales.

37 CPJI: Exchange of Greek and Turkish Populations, 1925, p. 20; Interpretation of the Convention Between Greece and Bulgaria Respecting Reciprocal Emigration, Signed at Neuilly-Sur-Seine on November 27th, 1919 (Question of the 'Communities'), 1930, p. 25. 
miento jurídico interno deben adoptar las medidas necesarias para una adecuada convergencia y compatibilidad con el orden internacional. El Estado debe determinar, en virtud de sus facultades soberanas, la manera de hacer efectivos los compromisos internacionales, lo que implica en materia de derechos humanos, garantizar su respeto y goce a todas las personas bajo su jurisdicción. ${ }^{38}$ En el caso de Chile, es pertinente destacar que el Gobierno apoyó expresamente la inclusión del artículo $2^{\circ}$ en la $\mathrm{CADH}^{39}$

Luego, en materia de protección efectiva de los derechos de las personas migrantes, especial cuidado de armonización debiese existir entre la normativa interna del Estado parte y los artículos 7, 8, 17 y 22 de la $\mathrm{CADH}$, a fin de garantizarles en procedimientos de expulsión, el debido respeto a su dignidad humana en condiciones igualitarias con los nacionales del Estado receptor y en consideración de su particular situación de vulnerabilidad.

Si bien la Constitución chilena reconoce a la familia como núcleo fundamental de la sociedad como base de la institucionalidad chilena (artículo $1^{\circ}$ inciso $2^{\circ}$ ) y asegura a todas las personas la igual protección de la ley en el ejercicio de sus derechos (artículo $19 n^{\circ} 3$ ) y el derecho a la libertad personal y a la seguridad individual (artículo $19 \mathrm{n}^{\circ} 7$ ), garantías aplicables por ende también a los migrantes que se encuentran dentro de la jurisdicción del Estado, de conformidad a la interpretación que el propio Tribunal Constitucional ha realizado en requerimiento de inaplicabilidad

38 Cfr. Steiner y URibe (2014), p. 8; Nogueira (2017), p. 147.

39 Conferencia especializada interamericana sobre derechos humanos, Actas y documentos, San José, 7-22 noviembre de 1969, OEA/Ser.K/XVI/1.2, observaciones del gobierno de Chile al proyecto de Convención sobre derechos humanos, p. 38, observación $1^{\circ}$, [fecha de consulta: 5 de febrero de 2018]. [Disponible en: https://www.oas.org/es/cidh/docs/enlaces/conferencia\%20 interamericana.pdf].

Como destaca Ferrer y Pelayo (2014), p. 75, "esta obligación no se encontraba en las fases previas de elaboración del proyecto de la Convención Americana, ya que se consideraba que existía naturalmente por aplicación del derecho internacional", lo cual ha sido reconocido por la CtIDH en varias oportunidades (CtIDH: serie $C n^{\circ} 39,27$ de agosto de 1998, pár. 68; serie $C n^{\circ}$ 166, 4 de julio de 2007, pár. 55, y serie $C n^{\circ} 162,29$ de noviembre de 2006, pár. 170), ídem., p. 97 : "[e]n el derecho de gentes, una norma consuetudinaria prescribe que un Estado que ha celebrado un convenio internacional, debe introducir en su derecho interno las modificaciones necesarias para asegurar la ejecución de las obligaciones asumidas". 
por inconstitucionalidad del Decreto Ley N 1094 de 1975 que establece normas sobre extranjeros en Chile ${ }^{40}$, aún no se verifica en plenitud un cumplimiento cabal del artículo 2 de la $\mathrm{CADH}$, en tanto la ley migratoria indicada no recoge un enfoque de derechos humanos, por lo que omite referencia a los derechos y mecanismos de protección efectivos de los derechos de los migrantes ${ }^{41}$.

En efecto, es posible observar además de una falta de reconocimiento expreso de la reunificación familiar como derecho de las personas migrantes, una mezquina regulación de las garantías judiciales del debido proceso y acceso a la justicia, en tanto la acción de reclamación judicial especial prevista en el artículo 89 del Decreto Ley № 1094 de 1975 adolece de restricciones y plazos que en la práctica no la hacen efectiva ${ }^{42}$ : $1^{\circ}$. Solo procede en contra de expulsiones ordenadas por decreto supremo del Ministerio del Interior ${ }^{43} ; 2^{\circ}$. El plazo para su interposición es brevísimo, solo de 24 horas desde que toma conocimiento de la orden de expulsión o abandono del país ${ }^{44} ; 3^{\circ}$. Corte Suprema (en adelante CS) co-

40 Tribunal Constitucional, rol $n^{\circ} 2273-12,4$ de julio de 2013, considerandos $28^{\circ}$ y 29.

41 Cfr. Domínguez (2016), p. 195; Díaz (2016), p. 182; Bassa y Torres (2015), p. 106.

42 Cfr. Díaz (2016), pp. 206 y 207; Bassa y Torres (2015), p. 118. Chiarello (2013), p. 183, destaca que "en todo procedimiento migratorio, sea de índole judicial, penal, administrativo u otro, es responsabilidad de las autoridades aplicar el principio del debido proceso de manera íntegra a fin de proteger y garantizar los derechos fundamentales de las personas migrantes involucradas y asegurar la igualdad ante los tribunales y cortes de justicia (...) En el caso de Chile, se han constatado varias falencias en la aplicación del debido proceso para procedimientos que involucran a extranjeros. Las más denunciadas han sido la falta de acceso a intérpretes y la imposibilidad de disponer del tiempo necesario para la defensa".

43 Luego, no se puede interponer esta acción especial de reclamación si la expulsión ha sido decretada por el Intendente, mediante resolución. Esto es, en el caso de: a) titulares de permiso de turismo o quienes prolonguen su permanencia con dicho permiso vencido, de conformidad con el artículo 84 inciso $2^{\circ}$ del Decreto Ley $\mathrm{N}^{\circ} 1094$ de 1975; y, b) extranjeros que hayan ingresado o intentado ingresar al país clandestinamente, de acuerdo con el Decreto $\mathrm{N}^{\circ} 818$ del Ministerio del Interior de 1983, actualizado por el Decreto $N^{\circ} 2911$ de 2000.

DomíngUEZ (2016), p. 200, destaca la inexistencia de justificación para distinguir entre las expulsiones impuestas por resolución exenta del Intendente Regional y las ordenadas por decreto supremo fundado del Ministerio del Interior, y la consecuente denegación de la acción especial respecto de las primeras.

44 Domínguez (2016), p. 200, destaca la inexistencia de una obligación para la Policía de Investigaciones de informar sobre los recursos disponibles y, además, solo puede ser interpuesto por el interesado o su familia, pudiendo estar el primero privado de libertad durante la tramitación del recurso y la familia generalmente fuera del territorio nacional. 
noce en única instancia ${ }^{45}$. Además, omite referencia a aspectos básicos del debido proceso que deben respetarse en casos de deportación de extranjeros, esto es: información detallada sobre el motivo de la deportación y, posibilidad de acceder a asistencia consular, a asesoría letrada gratuita y a un intérprete. Con todo, se establece la privación de libertad del extranjero mientras dure la tramitación de la acción, sin especificarse referencia a las garantías mínimas del derecho a no ser privado de libertad ni a los resguardos pertinentes para proteger su integridad personal.

Así las cosas, la acción de amparo se ha convertido en una vía idónea de reclamación en casos de expulsión de extranjeros, y durante el período $2008-2018^{46}$ se registra un aumento progresivo de interposiciones de esta acción, y proporcionalmente se recurre a ésta más que a la acción de reclamación especial del artículo 89 del Decreto Ley Nº 1094 de 1975. A continuación, se presenta tabla de elaboración propia ${ }^{47}$ que detalla el

Por lo demás, la CS realiza un control sumamente formalista

45 Chiarello (2014), p. 184, afirma que, "la ausencia del principio de la doble instancia en los casos de reclamo contra una notificación de expulsión ha sido una situación ampliamente denunciada por algunas organizaciones de la sociedad civil". Sin embargo, NAVARRo (2013) pp. 141 y142, resalta que la jurisprudencia del Tribunal Constitucional ha decidido que resolver en única instancia "no importa una infracción al debido proceso, desde que se contempla una etapa administrativa previa" (Tribunal Constitucional, rol $n^{\circ}$ 1252-2008, 28 de abril de 2009), "aunque nuestra Constitución exige un debido proceso que consagre la revisión de las sentencias, ello no significa el derecho a la doble instancia" (Tribunal Constitucional, rol n 1432-2009, 5 de agosto de 2010).

$46 \mathrm{La}$ muestra de sentencias recogidas incluye un período de 10 años desde marzo del 2008 a marzo del 2018, ya que el 9 de abril de 2018 se inicia un proceso de regularización de los migrantes en situación irregular, por lo que a partir de esa fecha las acciones judiciales presentadas para revisar órdenes de expulsión son acogidas por esta circunstancia. Cfr. Resolución Exenta $N^{\circ} 1.965$ de 2018.

47 Los datos se obtienen a partir de requerimiento de información presentado el 9 de mayo de 2018 en la Dirección de Comunicaciones de la CS, en el cual se solicita detalle con rol de las apelaciones de amparo en materia de migrantes y expulsión de extranjeros, período de 10 años hasta marzo del año 2018 inclusive, y reclamaciones judiciales por expulsión del país, mismo período. Luego, la base de datos de amparos recibida contiene 7372 casos con sus respectivos roles, la cual fue depurada por la autora a través de la consulta unificada de causas de CS, ya que el sistema de tramitación de la mencionada Corte no dispone de la posibilidad de obtener la información con detalle de materias por las cuales se interpone una apelación de recurso de amparo. Se previene que la muestra excluye aquellos amparos que no fueron elevados en apelación a la CS, ya que el propósito es comparar aquellos casos conocidos por la CS, sea vía apelación en el amparo o vía acción especial de reclamación del artículo 89 del Decreto Ley № 1094 de 1975. Los casos de amparo han sido clasificados, por materia, en casos de expulsiones y casos de prohibiciones de ingreso; y de acuerdo con sus resultados, en acogidos y rechazados. 
fenómeno descrito:

\begin{tabular}{|lcccccccccccc|}
\hline $\begin{array}{l}\text { Tipo de } \\
\text { acción }\end{array}$ & 2008 & 2009 & 2010 & 2011 & 2012 & 2013 & 2014 & 2015 & 2016 & 2017 & 2018 & Total \\
$\begin{array}{l}\text { Amparo } \\
\text { Art. 21 CPR }\end{array}$ & 1 & 2 & 4 & 6 & 12 & 67 & 57 & 73 & 82 & 166 & 60 & 530 \\
$\begin{array}{l}\text { Reclamación } \\
\text { art. 89 DL } \\
1094\end{array}$ & 4 & 13 & 22 & 25 & 24 & 24 & 16 & 5 & 5 & 4 & 4 & 146 \\
\hline
\end{tabular}

Por otra parte, es pertinente destacar que el texto del proyecto de Ley de Migración y Extranjería (Boletín N 8970-06) aprobado en primer trámite constitucional por la Cámara de Diputados ${ }^{48}$, y que se encuentra en segundo trámite constitucional en el Senado con su discusión general aprobada $^{49}$, incluye un listado de derechos de los extranjeros, entre ellos, la reunificación familiar (artículo 19) y el debido proceso (artículo 21), con el expreso objeto de promover el respeto y garantía de los derechos humanos de los extranjeros que se encuentren en Chile, sin importar su condición migratoria (artículo 3); asegurar el interés superior del niño (artículo 4); proporcionar a los extranjeros información íntegra y oportuna acerca de los procedimientos migratorios (artículo 5); y con expresa referencia a las obligaciones establecidas en los tratados internacionales ratificados por Chile y que se encuentren vigentes (artículos 3, 4, 21), además de precisar que la normativa migratoria se interpretará conforme a la Constitución y las normas internacionales de derechos humanos (artículo 10) y el principio pro homine (artículo 11). Por tanto, se observa se encuentra en una mayor armonización con los estándares interamericanos de protección de las personas migrantes en comparación con el Decreto de Ley 1.094 de 1975 en actual vigencia.

Por otra parte, en cuanto a la tutela judicial efectiva, hay que destacar que el artículo 138 del texto del proyecto, tras su discusión en la Comisión de Gobierno Interior, Nacionalidad, Ciudadanía y Regionalización, el

48 Cámara de Diputados, Legislatura 366, sesión 126, Oficio n 14.470 de 16 de enero de 2019. 49 Senado, Legislatura 367, sesión 40, Diario de sesiones del Senado, de 13 de agosto de 2019. 
cual consideraba una acción especial de reclamación en caso de órdenes de expulsión ${ }^{50}$, fue rechazado en la discusión particular del proyecto, en primer trámite constitucional en la Cámara Baja, por lo que quedó eliminado del texto. ${ }^{51}$ Tras esta negativa, ha quedado una inconsistencia en el proyecto de ley ingresado a segundo trámite constitucional al Senado, entre el artículo 129 sobre forma de disponer de la medida de expulsión y el artículo 136 sobre recursos, el cual por lo demás debiera cambiar su intitulado de "Recursos administrativos" a "Recursos administrativos y judiciales". En efecto, al contrastar ambos artículos ha quedado la siguiente desarticulación: del artículo 129 se desprende la posibilidad de interponer descargos en contra de la medida de expulsión en sede administrativa, mientras que en el artículo 136 se indica que respecto de la medida de expulsión solo se podrá reclamar judicialmente ${ }^{52}$.

50 Proyecto de Ley de Migración y Extranjería (Boletín $n^{\circ}$ 8970-06), texto con modificaciones de la Comisión de Gobierno Interior, Nacionalidad, Ciudadanía y Regionalización, artículo 138: "Los extranjeros afectados por una medida de expulsión sólo podrán reclamar judicialmente la legalidad o arbitrariedad de ésta. La reclamación podrá efectuarla el afectado por dicha medida por sí o por cualquier persona en su nombre, ante la Corte de Apelaciones del domicilio del reclamante, dentro del plazo de 10 días, contado desde la notificación de la resolución respectiva. // Dicho recurso deberá ser fundado y la Corte de Apelaciones respectiva fallará la reclamación en primera instancia, en cuenta, la que será agregada extraordinariamente a la tabla más próxima, gozando de preferencia para su vista y fallo, debiendo resolver el asunto dentro de tercero día. Su interposición suspenderá la ejecución de la orden de expulsión. // Los extranjeros afectados por una medida de expulsión tendrán derecho a la defensa jurídica a través de las Corporaciones de Asistencia Judicial, en igualdad de condiciones que los nacionales, de conformidad a las normas que las regulan".

51 Cfr. Publicación oficial de redacción de sesiones de la Cámara de Diputados, Legislatura $366^{\mathrm{a}}$, Sesión $126^{\mathrm{a}}$, 16 de enero de 2019, pp. 130 y 131. Asimismo, Cámara de Diputados, Oficio $\mathrm{n}^{\circ} 14.470$ de 16 de enero de 2019, Título X De los Recursos.

52 Proyecto de Ley de Migración y Extranjería (Boletín n 8970-06) aprobado en primer trámite constitucional por la Cámara de Diputados, Cámara de Diputados, Legislatura 366, sesión 126, Oficio $n^{\circ} 14.470$ de 16 de enero de 2019, artículo 129: "Forma de disponer la medida. Las medidas de expulsión y retorno asistido de extranjeros serán impuestas por resolución fundada del Director Nacional del Servicio. El Director Nacional del Servicio, por resolución, podrá designar las regiones del país en las cuales las medidas de expulsión y retorno asistido de titulares de permanencia transitoria serán impuestas por los directores regionales respectivos. Sólo en el caso que al afectado por la expulsión no le fuere aplicable lo prescrito en los incisos segundo y tercero del artículo 89 [rechazo o revocación de visado y posterior orden de abandono], previamente a la dictación de la medida deberá ser notificado en conformidad al artículo 143 y tendrá un plazo de diez días para presentar sus descargos respecto de la causal de expulsión invocada. En la notificación señalada precedentemente o en los incisos segundo y tercero del artículo 89, se le informará al extranjero que, de aplicarse la medida de expulsión, podrá, conforme a la legislación 
Al respecto, estimamos que no es conveniente una acción de reclamación especial bajo los términos propuestos por la Comisión de Gobierno Interior, Nacionalidad, Ciudadanía y Regionalización en la Cámara de Diputados (artículo 138), ya que siendo igualmente procedente la interposición de la acción constitucional de amparo, sería suficiente con que este sea el mecanismo de reclamación judicial dispuesto, más aún si este no contempla un plazo de interposición, sino que puede ejercerse en tanto se encuentre vigente la orden de expulsión que perturba la libertad de circulación del extranjero, y además procede en contra de todo tipo de expulsión, independiente del órgano que lo ordene, ya sea por decreto supremo o resolución administrativa. Sin embargo, como sabemos, aún falta la discusión particular del proyecto en segundo trámite constitucional en el Senado, por lo que la creación o no de una acción de reclamación especial en caso de expulsión aún no se encuentra zanjada. De decidirse por nuestro legislador, en definitiva, que se debe incorporar la referida acción en la ley de migraciones en discusión, ésta debiese considerar incorporar elementos para un debido proceso, tales como la posibilidad de contradictorio, en una instancia doble, que se pueda interponer por cualquier persona en nombre del afectado, mientras la afectación persista, a fin de reclamar por la medida de expulsión -ya sea porque ha sido dictada en contravención de ley o de forma arbitraria-, en un procedimiento ante autoridad competente, de rápida tramitación y que considere la posibilidad de otorgar al reclamante asistencia gratuita, asistencia consular y un intérprete o traductor, si la persona afectada no habla nuestra lengua.

aplicable, designar un mandatario que lo represente en defensa de sus derechos laborales y o previsionales, así como en el cumplimiento de sus obligaciones pendientes. Excepcionalmente, y sólo en casos debidamente calificados, fundados en razones de seguridad interior o exterior, podrá disponer el Subsecretario del Interior, mediante resolución fundada, la medida de expulsión de extranjeros. El acto administrativo de este último estará afecto al trámite de toma de razón, y deberá establecer el plazo de prohibición de ingreso al país, el que, fundado en razones graves y calificadas, podrá ser indefinido" y artículo 136: "Recursos administrativos. Los extranjeros afectados por alguno de los actos y o resoluciones establecidas en la presente ley, exceptuando la medida de expulsión, podrán interponer los recursos establecidos en la ley $\mathrm{N}^{\circ} 19.880$, que Establece Bases de los Procedimientos Administrativos que rigen los Actos de los Órganos de la Administración del Estado. // Ello, sin perjuicio de los demás recursos y acciones judiciales que procedan". 
Continuando con el contraste entre el proyecto de ley en comento y los estándares interamericanos, se destaca que dispone expresamente como criterio de ponderación a considerar por la Administración al fundamentar la dictación de una medida de expulsión, a la unidad familiar (artículo 125). Asimismo, contempla expresamente la prohibición de expulsiones colectivas (artículo 126).

\section{Aplicación del estándar interamericano de protección de las personas migrantes en casos de expulsión por los tribunales superiores de justicia chilenos}

El cumplimiento de buena fe de las normas internacionales (principio pacta sunt servanda) y la imposibilidad de invocar disposiciones de derecho interno para sustraerse de las obligaciones internacionales (artículo 27 de la CVDT) son principios que también se ven reflejados en el ámbito jurisdiccional, en tanto los tribunales nacionales debiesen aplicar directamente la $\mathrm{CADH}$, y la interpretación auténtica que ha realizado la $\mathrm{CtIDH}$ respecto de la determinación de su contenido y alcance, en casos judiciales atingentes a situaciones de deportación de extranjeros. ${ }^{53}$ De esta manera, no solo se estaría cumpliendo con el mandato de los artículos 1 y 2 de la $\mathrm{CADH}$, de hacer efectiva la protección de los derechos de todas las personas ${ }^{54}$, sino también, si la judicatura nacional sigue los criterios de la jurisdicción interamericana puede evitar la activación de un procedimiento contencioso ante la Comisión IDH por parte de las personas

53 Cfr. NASH y NúNEEZ (2017b), pp. 199 y 200, refieren a casos en el derecho comparado (Argentina, Colombia, Perú), en los cuales se adoptan medidas jurisdiccionales; tanto en la tramitación de los casos como en la resolución sustantiva de los mismos a la luz del contenido y alcance de los derechos humanos consagrados en los instrumentos internacionales.

54 NASH y NúNEEZ (2017a), pp. 17-19, sobre el carácter complementario entre los sistemas de protección de los derechos humanos nacional e internacional.

Por otra parte, GALDÁmEZ (2014), p. 331, añade que quienes propician el reconocimiento de la obligatoriedad de los criterios interpretativos de la Corte, no solo invocan los arts. 1 y 2 de la $\mathrm{CADH}$, sino también el art. $62 \mathrm{~N}^{\circ} 3$ de la Convención. También, "se invoca el Decreto $N^{\circ} 873$ de 5 de enero de 1981 que aprueba la Convención y que señala: 'b) El gobierno de Chile declara que reconoce como obligatoria de pleno derecho la competencia de la CtIDH respecto de los casos relativos a la interpretación y aplicación de esta Convención de conformidad con lo que dispone su artículo 62". En el mismo sentido, HenRíquez (2018), p. 353, también alude al artículo 29 de la $\mathrm{CADH}$. 
afectadas en sus derechos por actuaciones de funcionarios estatales, y puede concluir en que la $\mathrm{CtIDH} .^{55}$

La propia CtIDH, desde el Caso Almonacid, fallado el año $2006^{56}$, se ha referido al impacto o valor de su jurisprudencia en los foros internos y cómo las obligaciones internacionales alcanzan las labores de los jueces nacionales, aseverando además que la norma internacional y su interpretación, constituyen el estándar normativo cuyo cumplimiento puede ser exigido y que debe ser observado por los Estados. ${ }^{57}$ Idea que ha sido reiterada en las sentencias sobre migración que se analizan en este estudio. ${ }^{58}$

Por su parte, nuestra judicatura, y en especial la CS, reconoce como parámetro de convencionalidad a los derechos consagrados en los tratados internacionales, la costumbre internacional y a las normas de ius cogens. Y si bien no hace referencia expresa al valor de la jurisprudencia internacional como parámetro de convencionalidad, sí se refiere a que

55 Nogueira (2017), p. 146; Ferrer (2016), pp. 343 y 344; Steiner y URibe (2014), p. 7.

$56 \mathrm{CtIDH}$, serie $\mathrm{C} \mathrm{n}^{\circ} 154,26$ de septiembre de 2016, pár. 124: "cuando un Estado ha ratificado un tratado internacional como la Convención Americana, sus jueces, como parte del aparato del Estado, también están sometidos a ella, lo que les obliga a velar porque los efectos de las disposiciones de la Convención no se vean mermadas por la aplicación de leyes contrarias a su objeto y fin, y que desde un inicio carecen de efectos jurídicos (...) En esta tarea, el Poder Judicial debe tener en cuenta no solamente el tratado, sino también la interpretación que del mismo ha hecho la Corte Interamericana, intérprete última de la Convención Americana".

57 Cfr. Henríquez (2018); Benavides (2017), pp. 369-371; García Jaramillo (2016), pp. 144-146; García Ramirez (2016), pp. 173-180; Ferrer (2016), pp. 340-342; Olano (2016), pp. 87-89; Núñez (2015), p. 136; Durango y Garay (2015), pp. 110-113; Ferrer y Pelayo (2014), p. 98; Henríquez (2014), p. 120-123; Ferrer y Sánchez (2013), 45 pp; Ferrer (2011), pp. 562-567.

58 “(...) las autoridades internas están sujetas al imperio de la ley y, por ello, están obligadas a aplicar las disposiciones vigentes en el ordenamiento jurídico. Pero cuando un Estado es parte de un tratado internacional como la Convención Americana de Derechos Humanos, todos sus órganos, incluidos sus jueces, también están sometidos a aquél, lo cual les obliga a velar porque los efectos de las disposiciones de la Convención no se vean mermados por la aplicación de normas contrarias a su objeto y fin. Los jueces y órganos vinculados a la administración de justicia en todos los niveles están en la obligación de ejercer ex officio un 'control de convencionalidad' entre las normas internas y la Convención Americana de Derechos Humanos, evidentemente en el marco de sus respectivas competencias y de las regulaciones procesales correspondientes. En esta tarea, los jueces y órganos vinculados a la administración de justicia deben tener en cuenta no solamente el tratado, sino también la interpretación que del mismo ha hecho la Corte Interamericana, intérprete última de la Convención Americana de Derechos Humanos". Cfr. CtIDH: serie C $n^{\circ} 282,28$ de agosto de 2014, pár. 311; serie C n²18, 23 noviembre 2010, pár. 287. 
éste está compuesto por todas las fuentes del derecho, y que en virtud del artículo 38 del Estatuto de la Corte Internacional de Justicia incorpora las resoluciones judiciales como medio auxiliar de la determinación de las reglas de derecho. ${ }^{59}$

Se trataría de una "especie de control de convencionalidad", entendido como un mandato de interpretación de las normas internas conforme a lo dispuesto en la CADH y de la interpretación que la CtIDH ha hecho de la misma, construcción interpretativa plausible que permita armonizar la $\mathrm{CADH}$ y la jurisprudencia interamericana con el ordenamiento jurídico interno.

Sobre el control de convencionalidad, su origen, fundamento, aplicabilidad y efectos, existe gran discusión en la literatura, por tanto, creemos conveniente detenernos para resaltar aquellos aportes que creemos más significativos de tener en consideración, antes de puntualizar nuestra postura.

Enfaticemos que, entre la interpretación de las normas internas conforme a las normas internacionales y su interpretación auténtica, y el control difuso de convencionalidad existen estrechos vínculos. Respecto de este último, existen diversos grados de intensidad o realización, dependiendo de las competencias de cada juez y del particular sistema de control constitucional previsto por cada Estado. Así, el control difuso de constitucionalidad no consiste simplemente en dejar de aplicar la norma nacional por ser contraria al parámetro de convencionalidad, sino que implica, en primer término, tratar de armonizar la norma nacional con la convencional; lo cual significa realizar una interpretación conforme de la

59 NúNEEz (2015), pp. 164 y 165. En efecto, Steiner y URIBE (2014), p. 11 destacan que "las decisiones judiciales son medios auxiliares para la determinación del contenido del derecho internacional. De forma general los tribunales internacionales no crean derecho, únicamente lo interpretan, y sus decisiones sólo son vinculantes para las partes dentro del procedimiento, sin embargo, la interpretación que el tribunal internacional realice sobre una norma principal ya sea que ésta se encuentre en un tratado, sea parte del derecho consuetudinario internacional o sea un principio general del derecho internacional, será un mecanismo para dar contenido a ese derecho. Las decisiones judiciales son de gran importancia para el derecho internacional de los humanos, pues al no existir órganos legislativos globales, gran parte del desarrollo de los derechos humanos se ha llevado a cabo por estos órganos". 
norma nacional con la CADH y su interpretación auténtica como estándar mínimo, para desechar aquellas interpretaciones contrarias o incompatibles al parámetro convencional; por lo que, en realidad, se realiza un control de la interpretación que no cubra dicho parámetro. Y este ejercicio de compatibilidad lo puede realizar cualquier juez dentro de sus respectivas competencias, quedando reservada la inaplicación o declaración de invalidez de la norma inconvencional, exclusivamente a los jueces que dentro del sistema nacional tengan competencia para ello. ${ }^{60}$

Así, es posible clasificar al control de convencionalidad interno difuso, de acuerdo con su intensidad en máximo, intermedio y mínimo. El máximo tendrá lugar en los tribunales constitucionales, ya que tendrán la facultad de declarar la invalidez de la norma con efecto erga omnes. El intermedio ocurrirá en aquellos ordenamientos en los cuales se encuentra establecido un control de constitucionalidad difuso, ya que todos los jueces tendrían la competencia para inaplicar una ley inconvencional en el caso concreto, control que operará solo si no fue posible la interpretación conforme con la CADH. El control mínimo se producirá en caso de que los tribunales no tengan competencia alguna de control, por tanto, no pueden dejar de aplicar la norma interna, sin embargo, deberán utilizar la técnica hermenéutica de la interpretación conforme a la $\mathrm{CADH} .{ }^{61}$

Para simplificar la figura, es posible clasificar a la doctrina relevante en dos posturas, aquella que considera al control de convencionalidad como

60 FERRER (2011), pp. 534 y 535.

61 Ídem., p. 578.

BeNAVIDEs (2017), pp. 371 y 372 , destaca que a falta de competencia expresa en la CADH de los órganos jurisdiccionales en relación con el control de convencionalidad, "ésta debe ser interpretada de forma que no desvirtúe el sistema creado por los Estados al dar vida a la norma jurídica internacional. Los tribunales no tienen competencia para crear derecho más allá del vigente. Esto, sin embargo, no es obstáculo para aplicar interpretaciones evolutivas y dinámicas que redefinan derechos y sus contenidos, sin llegar a crear nuevos". Luego, ídem., pp. 377 y 378 , enfatiza que "en caso de contradicción o supuesta contradicción entre norma nacional o internacional, [existe] un problema de compatibilidad interpretativa y no de jerarquía, nulidad, vigencia o validez". Por tanto, "resultaría más apto hablar de control de compatibilidad (...) El operador nacional debe hacer convivir ambas normas, haciéndolas compatibles, mediante una interpretación armónica". Al respecto, hacemos presente que FERRER (2011), pp. 531, 535 y 562, ya se refería al control de convencionalidad difuso como un examen de compatibilidad entre actos y normas nacionales y la CADH. 
un control de tipo normativo cuyo efecto es declarar la inaplicabilidad o la invalidez de la norma interna inconvencional, y la otra que lo considera como un ejercicio de interpretación conforme a la Convención ${ }^{62}$, luego, de ser posible la armonización acarrea como consecuencia una protección del individuo de conformidad con el principio pro homine, pero si no es posible compatibilizarlas, el juez no puede desaplicar la norma interna, por lo que el efecto es la generación de responsabilidad internacional del Estado. ${ }^{63}$

Algunos destacan que nuestra Constitución no favorece un control de convencionalidad interno, ya que "a) no define la jerarquía de los tratados de derechos humanos; b) no explicita el criterio de interpretación conforme a los derechos consagrados en tratados ni el criterio de interpretación pro homine; c) no contiene una norma de incorporación de derechos implícitos; $y$ d) no reconoce valor de precedente vinculante a la jurisprudencia nacional ni internacional. Todas disposiciones que en otras Constituciones han facilitado el ejercicio del control de convencionalidad". ${ }^{64}$

No obstante, esta falta de explicitación en nuestra Constitución no imposibilita ni anula la implementación de los estándares internacionales de protección de los derechos humanos, ya que desde que el Estado ha ratificado y ha puesto en vigencia interna tratados internacionales sobre derechos humanos está obligado a ser consecuente con el objeto y fin de estos. En efecto, el artículo $5^{\circ}$ inciso $2^{\circ}$ de la Constitución, es “una declaración que establece deberes de respeto a los derechos humanos para todos los órganos del Estado y reconoce el carácter vinculante de los instrumentos de derecho internacional convencional", por tanto impone

62 Contreras (2015), pp. 434 y 435, califica a este tipo de control, interno y difuso, como un control de convencionalidad "débil", en cuanto a su intensidad y en diferenciación con el "fuerte", el cual importaría no solo una interpretación que permita la armonización con el derecho interno, sino una "obligación del juez nacional de 'desplazar' la aplicación de la norma interna por violar la $C A D H "$.

63 HeNRÍQUEZ (2014), pp. 132-137.

64 HenRIQuez (2018), pp. 352 y 353.

GALDÁmEZ (2014), pp. 354-356, en complemento, enumera las razones de porqué en la jurisdicción constitucional y en la doctrina nacional no se desarrolla el control de convencionalidad de manera sistemática, los cuales también son aplicables para la falta de desarrollo sostenido del control de convencionalidad difuso en los tribunales superiores de justicia. 
a la judicatura un deber general de respeto del derecho internacional, y un deber, particularmente en materia de derechos humanos, de interpretación sistemática y finalista, ya que se presume que el legislador no ha tenido la intención de infringir las obligaciones internacionales asumidas por el Estado. ${ }^{65}$ En definitiva, a nuestro juicio, en las relaciones del derecho internacional con el derecho interno, desde un enfoque de derechos humanos, se debe implementar la norma internacional, siempre que sea posible de compatibilizar por lo mandatado por nuestro sistema, con el afán último de alcanzar una efectiva y máxima protección de la dignidad humana. ${ }^{66}$

Luego, careciendo el sistema jurídico chileno de medidas legislativas que hagan una plena armonización con la CADH y tratándose de derechos especialmente aplicables a las realidades que padecen los migrantes en nuestro país, se hace necesario enfatizar que la obligación de respeto de los derechos en ésta garantidos y de adoptar medidas que los hagan efectivos, no solo recae sobre los órganos legislativos, sino en todos los poderes del Estado, incluidos los órganos jurisdiccionales internos. ${ }^{67}$

Sin embargo, la judicatura chilena, en casos de amparo en reclamación de expulsiones de extranjeros, no tiende a la aplicación directa de la $\mathrm{CADH}$, ni de la interpretación auténtica realizada por la CtIDH. En efecto, de la muestra de 530 sentencias que resuelven acciones de amparos interpuestos por extranjeros en situación de expulsión, en el período 20082018, solo 9 de ellas refieren a los estándares interamericanos como fuente integrante del plexo normativo a considerar, al interpretar el senti-

65 Díaz (2008).

En el mismo sentido, CAStilla (2013), pp. 92 y 93, propone referirse a lo que se ha llamado "especie de control de convencionalidad" con la expresión "garantía de tratados", en tanto desde que se incorpora la CADH al sistema jurídico nacional, se entienden aplicables los artículo 1, 2 y 29 de la misma, así "antes de exigirles a las autoridades vinculadas con la administración de justicia que lleven a cabo un contraste normativo", cree es mejor "buscar que primero apliquen y conozcan los tratados, que los interpreten y, si el sistema nacional se los autoriza, inapliquen las normas que atenten con los derechos humanos".

66 Para más detalle, vid. Diaz (2008). En el mismo sentido, CAstilla (2013), pp. 55 y 77.

67 Cfr. NAsh y NúÑEz (2017a), pp. 16 y 17; NASH y NúÑez (2017b), p. 201; Nogueira (2017), p. 147; García Jaramillo (2016), p. 148; Ferrer y Pelayo (2014), pp. 97 y 98; Hitters (2013), p. 695. 
do y alcance de los derechos fundamentales de las personas migrantes en materia de expulsión. ${ }^{68}$

A continuación, sistematizamos estas sentencias que aluden en sus considerandos al derecho internacional como parte de su raciocinio, destacando el estándar interamericano de protección de los derechos de las personas migrantes en situación de expulsión al que hacen referencia.

\subsection{Derecho a ser notificado de los motivos de la expulsión y revisión de sentencia desfavorable}

Uno de los estándares internacionales en la materia, de conformidad al artículo 22 en relación con el 7 y el 8 de la $C A D H$, es la posibilidad de recurrir de una decisión desfavorable tratándose del derecho de libertad personal, circulación y residencia. ${ }^{69}$ Cuestión que se reconoce el año 2014, a través de voto disidente en sentencia confirmatoria de la CS en amparo rechazado por el tribunal a quo, en cuanto aduce en su fundamentación normas convencionales de derecho internacional, especialmente el artículo 7 la CADH. Sin embargo, la referencia no es del todo correcta, en tanto el artículo $7 \mathrm{CADH}$ es aplicable en casos de detenciones practicadas en el contexto de la expulsión, lo que en los hecho no ocurría, aquí lo más acertado hubiera sido referir al artículo 22 de la $\mathrm{CADH}$, en cuanto se vulneró las garantías mínimas exigibles en un procedimiento de expulsión, pues el raciocinio del voto disidente califica la medida de expulsión de ilegal y arbitraria por haberse privado al recurrido de la posibilidad de impugnar el decreto de expulsión por la vía administrativa al no habérsele dado noticia debida de aquello. ${ }^{70}$

\footnotetext{
68 En siete casos las cortes aluden explícitamente a la $\mathrm{CADH}$, mientras que en dos de ellas solo de manera implícita aplican el estándar interamericano, pues solo se refieren expresamente al derecho internacional en general, sin especificar algún tratado en particular.

69 Artículo 84 inciso $1^{\circ}$ del Decreto Ley N 1094 de 1975 que "[l]a medida de expulsión de los extranjeros será dispuesta por decreto supremo fundado, suscrito por el Ministro del Interior bajo la fórmula 'Por orden del Presidente de la República', en el que se reservarán al afectado los recursos administrativos y judiciales legalmente procedentes" (el subrayado es nuestro).

$70 \mathrm{CS}$, rol $\mathrm{n}^{\circ} 3999-2014,19$ de febrero 2014 , considerandos $4^{\circ}$ y $5^{\circ}$.
} 


\subsection{Derecho a que la orden de deportación tenga fundamento legal}

Luego, en el resto de los casos pesquisados, en los cuales se hace referencia a normas de derecho internacional, nos encontramos con amparos acogidos, cuya ratio decidendi, en concordancia con el estándar interamericano de garantías mínimas cuya fuente es el artículo 22 de la $\mathrm{CADH}$-aunque no necesariamente se aluda expresamente a aquella disposición, sino en ocasiones en general al derecho internacional convencional-, versa sobre una falta de fundamento legal de la orden de abandono del país o decreto de expulsión, en su caso. ${ }^{71}$

Luego, debe existir una análisis de la legalidad de la causal de expulsión aplicada por la Administración, debiendo ponderarse la finalidad legítima e idoneidad de la medida, así también como su necesidad y proporcionalidad, pues es menester leer el artículo 22.6 de la CADH en consonancia con su pár. 3 , en tanto mandata que el derecho de circulación y de residencia solo puede ser restringido por ley y siempre que tal restricción sea indispensable en una sociedad democrática para la protección de determinados bienes jurídicos, tales como la seguridad nacional, la seguridad o el orden públicos, la moral o la salud públicas o los derechos y libertades de los demás. ${ }^{72}$

A continuación, se alude a los casos analizados que refieren a este estándar interamericano, sistematizándolos de acuerdo con el aporte específico que realizan en el desarrollo de la ratio decidendi en la materia.

71 De acuerdo con el artículo 22.6 de la $\mathrm{CADH}$, "[e]l extranjero que se halle legalmente en el territorio de un Estado parte en la presente Convención, sólo podrá ser expulsado de él en cumplimiento de una decisión adoptada conforme a la ley". En contraste, el artículo 84 inciso $1^{\circ}$ del Decreto Ley N 1094 de 1975 dispone que "Il]a medida de expulsión de los extranjeros será dispuesta por decreto supremo fundado, suscrito por el Ministro del Interior bajo la fórmula 'Por orden del Presidente de la República', en el que se reservarán al afectado los recursos administrativos y judiciales legalmente procedentes" (los subrayados son nuestros).

72 Artículo 22.3 y 6 de la CADH: "3. El ejercicio de los derechos anteriores no puede ser restringido sino en virtud de una ley, en la medida indispensable en una sociedad democrática, para prevenir infracciones penales o para proteger la seguridad nacional, la seguridad o el orden públicos, la moral o la salud públicas o los derechos y libertades de los demás (...) 6. El extranjero que se halle legalmente en el territorio de un Estado parte en la presente Convención, sólo podrá ser expulsado de él en cumplimiento de una decisión adoptada conforme a la ley". 
A. La discrecionalidad administrativa no puede devenir en arbitrarie$d_{a d}{ }^{73}$. Así, fallo de la CS del año 2015, el cual solo alude de manera genérica a los "[t]ratados [i]nternacionales sobre [d]erechos [h]umanos atingentes, suscritos y ratificados por Chile que se encuentran vigentes" como norma a la que debió atenderse para expresar algún fundamento razonable para la dictación del decreto de expulsión, de manera tal que no importara una discriminación arbitraria, al desatender el parámetro de conveniencia o utilidad que la autoridad administrativa debe considerar en el ejercicio de su potestad. ${ }^{74}$ En los hechos, una ciudadana argentina se encontraba trabajando con visa de turista ${ }^{75}$, hecho que autodenunció, sin embargo, la resolución de deportación "fundó su decisión en el hecho que la recurrente carece de los medios económicos para mantenerse en nuestro país, constituyéndose así en una carga social, antecedentes todos que conforme a lo señalado precedentemente no son efectivos, por lo que desaparece con ello el sustento fáctico y jurídico de la resolución"76. Si bien los extranjeros que trabajen en Chile sin la autorización respectiva o se encuentren con su visa vencida, pueden ser sancionados con multa, sin perjuicio de que puede disponerse por la autoridad administrativa su abandono obligado del país o su expulsión; estas son sanciones de carácter gradual y la discrecionalidad de la autoridad no puede constituir una arbitrariedad. ${ }^{77}$

B. Gravedad de la conducta que configura la causal de expulsión. En

73 NASH y NúÑez (2017a), p. 21, constatan que "en casos donde la ley entrega un espacio de discrecionalidad, tanto el Tribunal Constitucional como la CS han establecido un parámetro único: la discrecionalidad en ningún caso significa descontrol y, menos, arbitrariedad. Para definir cuál es la base de dicho control y cuál es el límite de la discrecionalidad para que no constituya arbitrariedad, los derechos humanos tienen un papel fundamental, en particular, aquellos que provienen de fuentes internacionales".

74 CS, rol n 3073-2015, 23 de febrero de 2015, considerando $4^{\circ}$.

75 De acuerdo con el artículo 71 del Decreto Ley $N^{\circ} 1094$ de 1975, los extranjeros que continúan residiendo en el país después de haberse vencido sus plazos de residencia legal pueden ser sancionados con multa de 1 a 20 sueldos vitales, sin perjuicio de que pueda disponerse su abandono obligado del país o su expulsión. Por su parte, el artículo 70 del citado Decreto, sancionan a los extranjeros que fueren sorprendidos desarrollando actividades remuneradas sin estar autorizados para ello, serán sancionados con multa de 1 a 50 sueldos vitales.

$76 \mathrm{CS}$, rol $\mathrm{n}^{\circ} 3073-2015,23$ de febrero de 2015 , considerando $3^{\circ}$.

77 Ídem., considerando $2^{\circ}$. 
concordancia con esta línea, la CS el $2015^{78}$, confirma fallo de la Corte de Apelaciones de Santiago (en adelante CAS) ${ }^{79}$, el cual también refiere de forma genérica a los tratados internacionales vigentes, pero en esta ocasión, especialmente al artículo 22 de la $\mathrm{CADH}$, en tanto la resolución de la autoridad administrativa no puede carecer de fundamentación, ya que debe "demostrar que la medida [de expulsión] adoptada resulta legal y razonable, es decir, que la conducta que se atribuye al extranjero configura alguna de las causales que autorizan la expulsión de quien (...) tenía residencia permanente en el país" ${ }^{\circ 0}$. En este caso, el extranjero tenía residencia definitiva desde el año 2009, y se decretó orden de expulsión en su contra a partir del año 2015 en consideración de condena del año 2011 por delito de robo con intimidación ${ }^{81}$, la Corte estima que la sola circunstancia de la condena, frente a su conducta posterior exenta de reproche y su arraigo familiar, deviene a la medida de expulsión en injustificada82. En efecto, "la hipótesis del artículo $15 N^{\circ} 2$ del Decreto Ley $N^{\circ} 1094$, en este caso por remisión del artículo 17 del mismo texto legal, exige para configura la causal que se ejecuten actos contrarios a la moral o a las buenas costumbres, esa supuesta conducta debe ser a lo menos asentada y calificada en cuanto a su gravedad por la autoridad con competencia para decidir acerca de la expulsión de un extranjero, es decir, si esta es acorde al fin que se persigue con ella (...) la ley exige dar contenido a la cláusula general, describiendo los acciones ejecutadas contra la moral y las buenas costumbres, es decir, se exige constatar un actuar que involucre una gravedad tal que amerita la expulsión, por las consecuencias particularmente negativas que tales conductas traen consigo para el interés general de la sociedad y los bienes protegidos". ${ }^{83}$

C. Situación actual de arraigo del extranjero recurrente. Desde el año 2013, los tribunales de justicia superiores chilenos han examinado la uti-

$78 \mathrm{CS}$, rol $\mathrm{n}^{\circ} 10035-2015,6$ de agosto de 2015,

79 CAS, rol n $1209-2015,27$ de julio de 2015 , considerandos $8^{\circ}$ y $9^{\circ}$.

80 Ídem., considerando $3^{\circ}$.

81 Ídem., considerando $1^{\circ}$.

82 Ídem., considerandos $7^{\circ}$ y $8^{\circ}$.

83 Ídem., considerando $7^{\circ}$. 
lidad y conveniencia de la residencia de una persona extranjera, no solo desde la perspectiva de la legalidad formal, sino distinguiendo si se está ante una actuación razonable y proporcionada, y si la expulsión es el medio idóneo a los fines que se busca resguardar, respetando consideraciones de orden humanitario y familiar. Así, la $\mathrm{CS}^{84}$ confirma fallo de la $\mathrm{CAS}^{85}$, en el cual la pareja de una ciudadana colombiana presenta solicitud de residencia sujeta a contrato, la cual fue denegada, aludiendo a una facultad privativa de la Administración, en atención a que la mujer presenta una condena por delito de falsedad material de documento público, delito prescrito y sin requerimientos judiciales pendientes, ordenando la expulsión inmediata. La Corte considera en la revisión del amparo interpuesto por su pareja, ciudadano chileno, con quien mantiene una relación de convivencia y esperan un hijo en común, que se espera nazca en dos meses más. En otro caso del mismo año ${ }^{86}$, recurren la cónyuge y dos hijas del extranjero ciudadano ecuatoriano expulsado, médico cirujano, condenado a dos años de presidio menor en su grado medio, por infracción a la Ley de Drogas, por prescribir sustancias estupefacientes, pena remitida que se encuentra cumplida. La CAS considera en el examen que el delito se había cometido hace 9 años, y que su familia, compuesta por cónyuge y dos hijas son todas de nacionalidad chilena, quienes se verían perjudicadas con la separación de su sostenedor económico. Por lo que funda la decisión en el artículo 17 de la CADH sobre protección de la familia.

Luego, en 2017, la CS $^{87}$ considera en el criterio jurisprudencial el arraigo del recurrente, al confirmar fallo de la $\mathrm{CAS}^{88}$ que continúa desarrollando esta línea argumental sobre la debida fundamentación de las medidas de expulsión y la ponderación de su necesidad y proporcionalidad. En este caso, la extranjera había hecho ingreso al país clandestinamente,

84 CS, rol n 805-2013, 4 de febrero de 2013.

85 CAS, rol $n^{\circ} 19-2013,21$ de enero de 2013 , considerandos $4^{\circ}$ y $11^{\circ}$.

86 CAS, rol $n^{\circ} 550-2013,22$ de abril de 2013 , considerandos $8^{\circ}$ a $11^{\circ}$. Confirmada sin más por la CS, rol n² 2837-2013, 22 de abril de 2013.

$87 \mathrm{CS}$, rol n 45.123-17, 19 de diciembre de 2017.

88 CAS, rol n³137-2017, 7 de diciembre de 2017. 
luego buscando regularizar su situación migratoria concurrió voluntariamente a las dependencias del Departamento de Policía Internacional para realizar el trámite de autodenuncia. Por su parte, la Intendencia Regional Metropolitana había denunciado el hecho al Ministerio Público, desistiéndose posteriormente de la acusación penal ${ }^{89}$. La Corte acoge el recurso deducido, porque considera que el decreto de expulsión es un acto desmedido, injustificado y desproporcionado respecto a los fundamentos que indica ${ }^{90}$; si bien la recurrente ingresó por un paso clandestino fue personalmente a autodenunciarse porque su idea de ingresar a nuestro país era buscar nuevas y mejores oportunidades de vida, por ello quiere regularizar su situación migratoria y permanencia en Chile, al momento de la autodenuncia hecha por la amparada, la Intendencia se desistió de la acción, extinguiéndose la responsabilidad penal, además la autoridad que dictó el decreto de expulsión "no consideró la situación de arraigo de la amparada, su tiempo de permanencia en el país y la actividad remunerada ejecutada" (se desempeña como asesora del hogar). ${ }^{91}$

El mismo criterio se sigue el año 2018 en causa acogida por la CAS $^{92}$,

89 De acuerdo con el artículo 69 del Decreto Ley $N^{\circ} 1094$ de 1975, los extranjeros que ingresen o egresen del país clandestinamente será sancionado con presidio menor en su grado máximo. Además, una vez cumplida la pena impuesta, los extranjeros serán expulsados del territorio nacional. Luego, según el artículo 78, tratándose de las investigaciones de hechos constitutivos de esta infracción migratoria constitutiva de delito, sólo podrán iniciarse por denuncia o querella del Ministerio del Interior o del Intendente Regional respectivo, más si se desisten de la denuncia o querella, se extingue la acción penal. En tal caso, el juez de garantía o el tribunal de juicio oral en lo penal dispondrá el inmediato cese de las medidas cautelares que se hubieren decretado: ¿Podría interpretarse que ello implica el levantamiento de las órdenes de abandono del país o decretos o resoluciones de expulsión?

Al respecto, interesante resulta, fallo de la Corte de Apelaciones de Copiapó, rol N²90-2015, 20 de octubre de 2015, que acoge amparo en caso de ingreso clandestino por paso no habilitado, por estimar que la denuncia y posterior desistimiento de la denuncia por parte de la Intendencia impide invocar la circunstancia como fundamento de una orden de expulsión posterior, ya que se coarta el debido proceso legal, derecho reconocido, entre otros, en el artículo $8^{\circ}$ de la CADH. Cfr. considerandos $7^{\circ}$ y $8^{\circ}$. En el mismo sentido, pero solo aludiendo en general "los tratados internacionales ratificados y vigentes en Chile", CS, rol n 16034-2016, 1 de marzo de 2016, considerando $2^{\circ}$.

90 CAS, rol $n^{\circ} 3137-2017,7$ de diciembre de 2017 , considerando $6^{\circ}$.

91 Ídem., considerandos $4^{\circ}$ y $5^{\circ}$.

92 CAS, rol n 262-2018, 1 de marzo de 2018. 
fallo confirmado por la $\mathrm{CS}^{93}$, en tanto el extranjero había sido condenado por delito de microtráfico a la pena de 61 días de presidio menor en su grado mínimo, la que fue cumplida bajo la modalidad de remisión condicional, tiene un hijo de nacionalidad chilena (también recurrente en la causa), posee visa temporaria y contrato de trabajo, pudiendo postular por el tiempo de residencia a un permiso definitivo, por tanto la medida deviene en desproporcionada y arbitraria, dado su arraigo social y la unidad familiar, en consideración del artículo 22 de la $\mathrm{CADH} .{ }^{94}$

\subsection{Derecho a no ser privado de libertad ilegal o arbitrariamente de forma previa a la expulsión}

En materia de detención de migrantes, se erige como sentencia emblemática, aquella que resuelve sobre la detención de 17 personas extranjeras en el cuartel policial de la Policía de Investigaciones de Chile (Cuartel Borgoño), el año 2013. La CAS para evaluar la legalidad de la privación de libertad reconoce que no se puede prescindir de los instrumentos de derecho internacional que protegen los derechos fundamentales, y en particular, del artículo 7 de la $\mathrm{CADH} .{ }^{95}$ Luego, resuelve la libertad inmediata de los detenidos pues la medida no solo era ilegal, por sobrepasar el plazo de detención máximo de 24 horas establecido por la ley, sino también arbitraria, por no haber sido necesaria ni proporcional. Además, asevera que las condiciones del lugar de detención eran "inadecuadas e indignas". ${ }^{96}$

No era una medida necesaria, pues si la detención tiene por único objeto facilitar el cumplimiento de la medida de expulsión es estrictamente funcional o instrumental. Toda detención debe ser de carácter excepcional, pues importa la afectación de un derecho fundamental; excepcionalidad que se incrementa en este caso en el cual la detención no está

$93 \mathrm{CS}$, rol n ${ }^{\circ} 3743-2018,12$ de marzo de 2018.

94 Ídem., considerandos $4^{\circ}$ y $5^{\circ}$.

95 CAS, rol $n^{\circ} 351-2013,9$ de marzo de 2013 considerandos $3^{\circ}$ y $4^{\circ}$.

96 Cfr. Ídem., considerando $10^{\circ}$ : "Los detenidos están virtualmente hacinados, deben dormir en el suelo, permanecen encerrados prácticamente todo el día, saliendo de sus celdas ocasionalmente para asearse o acudir al baño, el lugar es sombrío y con escasa ventilación, etcétera". 
visada por autoridad judicial. ${ }^{97}$ Tampoco, proporcional, en cuanto "todos ellos estaban cumpliendo los controles a que se refieren los artículos 164 y 165 de la Ley de Extranjería". Se entiende que la materialización de la expulsión puede tener demora de dos a tres semanas por las "necesidades de coordinación, de compra de pasajes o de asignación de equipos policiales, pero con las personas en libertad. Jamás recluidos por todo ese lapso". ${ }^{98}$

\section{Conclusiones}

1. El estándar interamericano de protección de los extranjeros en situación de expulsión, independiente de su estatus migratorio, está integrado por garantías mínimas procesales aplicables a la ejecución de la medida, la prohibición de realización de expulsiones colectivas de extranjeros y el principio de no devolución, y a la consideración especial de los principios del interés superior del niño y de la unidad familiar, en su caso.

1.1. Todos los extranjeros tienen derecho a que la adopción y aplicación de la medida de expulsión se ajuste a un debido proceso, lo cual incluye como mínimo el ser notificados de la decisión -fundada conforme la ley-, y de tener posibilidad de defenderse con asistencia letrada gratuita, asistencia consular y de un intérprete, de ser necesario. Esta defensa incluye el derecho de recurrir de la decisión desfavorable. Garantías mínimas procesales aplicables también, en caso de detención administrativa previa a la expulsión, a la privación de libertad.

1.2. Las expulsiones colectivas se encuentran prohibidas, ello no refiere al número de expulsados en un mismo decreto o resolución, sino a la obligación de un análisis de la situación individual de cada extranjero. También devolverlos en caso de constatación de un riesgo para su vida, integridad o libertad, independiente de si tiene o no la calidad de refugiado o asilado político.

1.3. En caso de expulsión de uno o ambos padres de un niño, en virtud de los principios del interés superior del niño y de la unidad familiar, se

97 Cfr. Ídem., considerando $9^{\circ}$.

98 Cfr. Ídem., considerando $11^{\circ}$. 
deben al menos analizar el tiempo de estadía en el Estado receptor, los lazos familiares -tipo de relación, tiempo y ejercicio de estos-, la nacionalidad de los miembros de la familia del extranjero sujeto a la medida de expulsión, perturbación que se causaría en la vida diaria del niño.

2. De conformidad con el artículo $2^{\circ}$ de la $\mathrm{CADH}$, las leyes migratorias de los Estados parte debiesen encontrarse en consonancia con sus artículos $7,8,17$ y 22 .

2.1. Si bien nuestra Constitución reconoce la protección de la familia y garantiza la igualdad ante la ley, el debido proceso y la libertad personal y seguridad individual, la ley de migraciones vigente (Decreto Ley N ${ }^{\circ} 1094$ de 1975) carece de un enfoque de derechos humanos, por lo que adolece de un reconocimiento expreso del derecho a reunificación familiar y de una tutela judicial efectiva en casos de expulsión.

2.2. Por su parte, el proyecto de ley sobre la materia, en actual tramitación (Boletín $N^{\circ} 8970-06$ ), si bien avanza significativamente en reconocimiento de derechos de los extranjeros y refiere expresamente a las obligaciones establecidas en los tratados internacionales ratificados por Chile e incluye cláusulas para su interpretación, aún no existe claridad sobre la aplicabilidad de recursos administrativos en contra de las expulsiones y la creación o no de una acción judicial especial de reclamación, su plazo de interposición y los derechos de solicitar, en tal contexto, asistencia consular y un intérprete o traductor, de requerirse.

3. Es importante que el Estado sea consciente de que es parte de un sistema internacional de protección de los derechos de las personas, y que actúe en consecuencia, en tal sentido, una alternativa posible siempre será la incorporación del estándar interamericano de protección a las personas migrantes por los jueces nacionales, con el afán último de alcanzar una efectiva y máxima protección de la dignidad humana.

3.1. Sin embargo, en Chile no existe una tendencia mayoritaria a la aplicación directa de la CADH en casos de deportación de personas migrantes. En el período analizado 2008-2018, de 530 sentencias solo 9 de ellas aluden al estándar interamericano ( 7 expresamente a la $\mathrm{CADH}$, 2 implícitamente refiriendo al derecho internacional en general sin mencionar un tratado en particular), lo que equivale a un $1,7 \%$ del total de la 
muestra y a un 3\% de los amparos acogidos. En contraste con los 231 amparos rechazados ( $44 \%$ del total de la muestra), casos en los cuales, de haberse implementado el plexo normativo internacional, quizás se hubiese facilitado una interpretación armónica del Decreto Ley N 1094 de 1975 con la CADH y podríamos haber tutelado en una mayor proporción los derechos de las personas migrantes.

3.2. No obstante, se destaca la ratio decidendi de los casos pesquisados que hacen referencia expresa al derecho internacional, razonamientos de nuestros tribunales superiores de justicia que se encuadran correctamente en el estándar interamericano de garantías mínimas de los procedimientos de expulsión de personas migrantes:

A. La decisión de deportación, sea bajo la forma de orden de abandono del país o de decreto o resolución de expulsión, debe ser fundada. Esta fundamentación debe ser de conformidad a la ley. Luego, se previene que si la ley de migraciones vigente (Decreto Ley $\mathrm{N}^{\circ} 1094$ de 1975) entrega facultades discrecionales a la Administración y causales de expulsión que atienden a criterios amplios e indeterminados como lo son "la conveniencia y utilidad para el país" o "ejecut[ar] actos contrarios a la moral o a las buenas costumbres", debe existir una ponderación de los elementos de hechos actuales que circundan la situación migratoria de la persona, tales como su arraigo social y familiar.

B. No basta que la medida de expulsión tenga un fundamento legal, sino también debe ser razonable, es decir, necesaria y proporcional, para que no se transforme en arbitraria. En tal sentido, por ejemplo, el haber ingresado clandestinamente al país, el trabajar sin autorización o con la visa vencida, o el haber cometido un delito, no justifican por sí solos la expulsión; en el primer caso, se revisa si se investigó y probó el delito, también se considera si ha existido desistimiento de la denuncia por parte de la Intendencia, pues ello extingue la responsabilidad de conformidad al artículo 78 del Decreto Ley № 1094 de 1975; en el segundo, se revisa si la persona se encuentra trabajando actualmente, si ha conformado una familia, y en general su comportamiento en la sociedad; en el tercero, la gravedad del delito, el tiempo transcurrido desde su comisión, el cumplimiento de la pena, la conducta posterior, la reinserción exitosa en la 
comunidad, si se encuentra trabajando, si tiene familia en Chile.

C. También se ha reconocido, aunque solo en voto disidente de un Ministro de la CS, la importancia de la debida notificación de la medida de expulsión, pues ello gatilla la posibilidad de revisión de la decisión desfavorable, garantía mínima de debido proceso en casos de deportación.

D. En caso de existir detención administrativa previa a la ejecución de la orden de expulsión, se ha de considerar que son aplicables los mismos estándares respecto de la medida de expulsión, es decir, garantías procesales mínimas para solicitar revisión judicial de la privación de libertad, criterios de legalidad y de arbitrariedad de la detención. Además, especialmente se consideran las normas de trato digno, incluyendo las condiciones de los lugares de detención. Finalmente, la medida de detención con el fin instrumental único de facilitar el cumplimiento de la expulsión debe ser de aplicación excepcional.

\section{Bibliografía}

Alfonso, César (2010): "La obligatoriedad de las decisiones de la Corte Interamericana de Derechos Humanos desde la perspectiva de distintos países de América del Sur", en Ambos, Kai, Malarino, Exequiel y ELSNer, Gisela (editores), Sistema Interamericano de Protección de los Derechos Humanos y Derecho Penal Internacional (Montevideo, Konrad-Adenauer-Stiftung) pp. 63-79.

Bassa Mercado, Jaime y Torres Villarrubia, Fernanda (2015): “Desafíos para el ordenamiento jurídico chileno ante el crecimiento sostenido de los flujos migratorios", en Estudios Constitucionales (vol. 13, n²), pp. 103-124.

BenadAVA, Santiago (1992): "Las relaciones entre derecho internacional y derecho interno ante los tribunales chilenos", en Nuevos enfoques del derecho internacional (Santiago, Editorial Jurídica de Chile) pp. 9-59.

—. (2004): Derecho Internacional Público (8ª edición, Santiago, Abeledo Perrot).

Benavides Casals, María Angélica (2017): "El control de compatibilidad y el control de convencionalidad (o el problema de la competencia)", en 
Estudios Constitucionales (vol. 15, $\mathrm{n}^{\circ}$ 2), pp. 365-388.

CASTLLA JUÁREZ, Karlos (2013): "¿Control interno o difuso de convencionalidad? Una mejor idea: la garantía de tratados", en Anuario Mexicano de Derecho Internacional (vol. XIII), pp. 51-97.

ChIARELLO, Leonir Mario (coordinador y editor) (2013): Las políticas públicas sobre migraciones y la sociedad civil en América Latina. Los casos de Bolivia, Chile, Paraguay y Perú (Nueva York, Scalabrini International Migration Network Inc.).

ConfoRTI, Benedetto (1995): Derecho Internacional (Traducc. Raúl Vinuesa, Buenos Aires, Zavalia).

Contreras VAsquez, Pablo (2015): "Análisis Crítico del Control de Convencionalidad", en Núñez Poblete, Manuel Antonio (ed.), La Internacionalización del Derecho Público (Santiago, Thomson Reuters) pp. 425-469.

- (2017): "Notas sobre el corpus juris interamericano", en NogueiRA, Humberto y AgulLaR, Gonzalo (coords.), Control de Convencionalidad, Corpus luris y lus Commune Interamericano (Santiago, Edit. Triángulo) pp. 145-157.

Díaz TolosA, Regina Ingrid (2008): "Pautas de interpretación de los tratados internacionales derivados del deber de promoción de los derechos humanos impuesto a la judicatura chilena por la Constitución Política", en Anuario de Derecho Constitucional Latinoamericano (vol. XIV), pp. 499-522.

-. (2015): Aplicación del ius cogens en el ordenamiento jurídico interno (Santiago, Thomson Reuters).

- (2016): "Ingreso y permanencia de las personas migrantes en Chile: Compatibilidad de la normativa chilena con los estándares internacionales", en Estudios Constitucionales (vol. 14, no 1), pp. 179-220.

Dominguez VALVERDE, Cecilia Andrea (2016): "Derecho chileno migratorio a la luz del derecho migratorio internacional", en Revista Chilena de Derecho (vol. 43, n 1), pp. 189-217.

Durango Álvarez, Gerardo y Garay Herazo, Kennier (2015): "El control de constitucionalidad y convencionalidad en Colombia", en Revista Prolegómenos, Derechos y Valores (vol.18, n 36), pp. 99-116. 
FERRER MAcGregor, Eduardo (2011): “Interpretación conforme y control difuso de convencionalidad. El nuevo paradigma para el juez mexicano", en Estudios Constitucionales (vol. 9, n² 2), pp. 531-622.

FERrer MAcGregor, Eduardo (2016): "El control de convencionalidad como un vehículo para el diálogo judicial entre la Corte Interamericana de Derechos Humanos y los tribunales de América", en Anuario de Derecho Constitucional Latinoamericano (vol. XXII), pp. 337-356.

Ferrer MacGregor, Eduardo y Pelayo Möller, Carlos (2014): “Artículo 2. Deber a Adoptar Disposiciones de Derecho Interno”, en STEINER, Christian y URIBE, Patricia (eds.), Convención Americana sobre Derechos Humanos. Comentario (Bogotá, Konrad Adenauer Stiftung) pp. 69-98. Ferrer Mac-Gregor, Eduardo y Sánchez GIL, Rubén (2013): "Módulo 4: Control difuso de constitucionalidad y convencionalidad", en Propuesta metodológica para la enseñanza de la reforma constitucional en materia de derechos humanos (México D.F., Suprema Corte de Justicia de la Nación, Oficina en México del Alto Comisionado de las Naciones Unidas para los Derechos Humanos y Comisión de Derechos Humanos del Distrito Federal) 45 pp.

GALDÁmEZ ZeLADA, Liliana (2014): "El valor asignado por la jurisprudencia del Tribunal Constitucional a la jurisprudencia de la Corte Interamericana de Derechos Humanos", en Estudios Constitucionales (vol. 12, $\left.n^{\circ} 1\right)$, pp. 329-364.

García JarAmillo, Leonardo (2016): "De la "constitucionalización" a la "convencionalización" del ordenamiento jurídico. La contribución del ius constitutionale commune", en Revista Derecho del Estado ( $\left.n^{\circ} 36\right)$, pp. 131-166.

García Ramírez, Sergio (2016): "Sobre el control de convencionalidad", en Pensamiento Constitucional ( $\left.\mathrm{n}^{\circ} 21\right)$, pp. 173-186.

Herdegen, M. (2005): Derecho Internacional Público (Traducc. M. Anzola, México D.F., Konrad-Adenauer-Stiftung y Universidad Nacional Autónoma de México).

Henríquez Viñas, Miriam (2014): "La polisemia del control de convencionalidad interno", en International Law, Revista Colombiana de Derecho Internacional (vol. 24), pp. 113-141. 
- (2018): "Cimientos, auge y progresivo desuso del control de convencionalidad interno: veinte interrogantes", en Revista Chilena de Derecho (vol. 45, n²), pp. 337-361.

HITTERS, Juan Carlos (2013): "Un avance en el control de convencionalidad. (El efecto 'erga omnes' de las sentencias de la Corte Interamericana)", en Estudios Constitucionales (vol. 11, n 2), pp. 695-710.

KotzUr, Markjus (2009): "Good Faith (bona fide)", Max Planck Encyclopedia of Public International Law, [fecha de consulta: 15 de enero de 2019]. [Disponible en: http://www.mpepil.com].

Molina Vergara, Marcela (2018): "Estándares jurídicos internacionales: necesidad de un análisis conceptual", en Revista de Derecho (Universidad Católica del Norte) (vol. 25, n 1), pp. 233-256.

NACIONES UNIDAS (2014): Informe de la Comisión de Derecho Internacional (Documentos Oficiales, Sexagésimo noveno período de sesiones, Suplemento $N^{\circ} 10$ (A/69/10), Nueva York, Asamblea General).

NASH RoJAS, Claudio (2013): "El principio pro persona en la jurisprudencia de la Corte Interamericana de Derechos Humanos", NogueIRA AlCALÁ, Humberto (coordinador), Diálogo judicial multinivel y principios interpretativos favor persona y de proporcionalidad (Santiago, Librotecnia) pp. 155-199.

Nash Rojas, Claudio y Núñez Donald, Constanza (2017a): "Los usos del derecho internacional de los derechos humanos en la jurisprudencia de los tribunales superiores de justicia en Chile", en Estudios Constitucionales (vol. 15, $\mathrm{n}^{\circ} 1$ ), pp. 15-54.

- (2017b): "Recepción formal y sustantiva del derecho internacional de los derechos humanos: experiencias comparadas y el caso chileno", en Boletín Mexicano de Derecho Comparado (nueva serie, año XLX, $\left.\mathrm{n}^{\circ} 148\right)$, pp. 185-231.

NAVARRo Beltrán, Enrique (2013): "El debido proceso en la jurisprudencia del Tribunal Constitucional de Chile", en Anuario de Derecho Constitucional Latinoamericano (vol. XIX), pp. 121-145.

Nogueira AlcalÁ, Humberto (2017): "El control de convencionalidad por los Estados parte de la Convención Americana sobre Derechos Humanos y tribunales chilenos", en Revista de Derecho (UCUDAL). $2^{a}$ 
época (vol. $\left.13 \mathrm{n}^{\circ} 15\right)$, pp. 143-200.

NúÑEz DonalD, Constanza (2015): "Bloque de constitucionalidad y control de convencionalidad en Chile: avances jurisprudenciales", en Anuario de Derechos Humanos ( $\left.\mathrm{n}^{\circ} 11\right)$, pp. 157-169.

Olano, H. (2016): "Teoría del control de convencionalidad", en Estudios Constitucionales (vol. 14, $\mathrm{n}^{\circ} 1$ ), pp. 61-94.

REINHOLD, Steven (2013): "Good faith in International Law", UCL Jornal of Law and Jurisprudence (vol. 2), pp. 40-63.

SAGÜÉs, Néstor (2003): "Las relaciones entre los tribunales internacionales y los tribunales nacionales en materia de derechos humanos. Experiencias en Latinoamérica", en lus et Praxis (vol. 9, n 1), pp. 205-221. SÁncheZ-RodAs, C. (2006): "Cuestiones atinentes al derecho a la reagrupación familiar de los extranjeros de terceros países en España como instrumento para su inserción socio-laboral", Revista del Ministerio de Trabajo y Asuntos Sociales ( ${ }^{\circ}$ 63): pp. 297-314.

SHAW, Malcolm N. (2008): International Law (6th edition, Cambridge, Cambridge University Press).

Sorensen, Max (ed.) (1973): Manual de Derecho Internacional Público (Traducc. a cargo de la Dotación Carnegie para la Paz Internacional, México D.F., Fondo de Cultura Económica).

Steiner, Christian y URIBe, Patricia (2014): "Introducción General", en SteIner, Christian y URIBE, Patricia (eds.), Convención Americana sobre Derechos Humanos. Comentario (Bogotá, Konrad Adenauer Stiftung) pp. 2-17.

Uprimny Yepes, Rodrigo y SÁnchez Duque, Luz María (2014): “Artículo 22. Derecho de Circulación y de Residencia”, en STEINER, Christian y URIBE, Patricia (eds.), Convención Americana sobre Derechos Humanos. Comentario (Bogotá, Konrad Adenauer Stiftung) pp. 531-551.

VIRAlly, Michel (1983): "Review Essay: Good Faith in Public International Law",en American Journal of International Law (vol. 77, $\mathrm{n}^{\circ} 1$ ), pp. 130-134.

Wehberg, Hans (1959): "Pacta sunt servanda", en American Journal of International Law (vol. 53, $\mathrm{n}^{\circ} 4$ ), pp. 775-786. 


\section{Normas jurídicas citadas}

Constitución Política de la República de Chile de 1980 actualizada con reforma del año 2005, Decreto 100 Fija el texto refundido, coordinado y sistematizado. Diario Oficial, 22 septiembre 2005.

Convención Americana sobre Derechos Humanos. San José de Costa Rica, 22 noviembre de 1969. Promulgada en Chile por Decreto Supremo № 873, Diario Oficial, 5 de enero de 1991.

Convención de Viena sobre el Derecho de los Tratados. Viena, 23 mayo 1969. Entrada en vigor 27 enero 1980. Promulgada en Chile por el Decreto Supremo $\mathrm{n}^{\circ} 381$ del Ministerio de Relaciones Exteriores, Diario Oficial, 22 junio 1981.

Decreto Ley $N^{\circ} 1094$, establece normas sobre extranjeros en Chile, de 19 de julio de 1975, actualizado al 8 de abril de 2011.

Decreto Supremo $N^{\circ} 818$, delega en autoridades de gobierno interior que indica, las atribuciones relativas a extranjeros, que señala, actualizado al 20 de mayo de 2000.

Resolución Exenta N 1965 del Ministerio del Interior y Seguridad Pública. Dispone proceso de regularización extraordinaria de permanencia en el país a extranjeros que indica, 9 de abril de 2018.

\section{Jurisprudencia citada}

Exchange of Greek and Turkish Populations (1925): Corte Permanente de Justicia Internacional, 21 de febrero de 1925, serie B $n^{\circ} 10$, [fecha de consulta: 18 de enero de 2019]. [Disponible en: http://www.worldcourts.com/pcij/eng/decisions/1925.02.21_greek_turkish.htm].

Interpretation of the Convention Between Greece and Bulgaria Respecting Reciprocal Emigration, Signed at Neuilly-Sur-Seine on November 27th, 1919 (Question of the 'Communities') (1930): Corte Permanente de Justicia Internacional, 31 de julio de 1930, serie B $\mathrm{n}^{\circ} 17$, [fecha de consulta: 18 de enero de 2019]. [Disponible en: http://www.worldcourts.com/pcij/eng/decisions/1930.07.31_greco-bulgarian.htm].

Treatment of Polish Nationals and Other Persons of Polish Origin or Speech in the Danzig Territory (1932): Corte Permanente de Justicia 
Internacional, 4 de febrero de 1932, series A/B $\mathrm{n}^{\circ} 44$, [fecha de consulta: 18 de enero de 2019]. [Disponible en: http://www.worldcourts.com/ pcij/eng/decisions/1932.02.04_danzig.htm]

Free Zones of Upper Savoy and the District Of Gex (1932): Corte Permanente de Justicia Internacional, 7 junio 1932, series A/B $n^{\circ} 46$, fecha de consulta: 18 de enero de 2019]. [Disponible en: http://www.worldcourts.com/pcij/eng/decisions/1932.06.07_savoy_gex.htm].

Caso Garrido y Baigorria vs. Argentina (1998): Corte Interamericana de Derechos Humanos, 27 de agosto de 1998. Serie C N³9.

Opinión Consultiva OC-6/86 sobre La Expresión "Leyes" en el Artículo 30 de la CADH (1986): Corte Interamericana de Derechos Humanos, 9 de mayo de 1986. Serie $A n^{\circ} 6$.

Opinión Consultiva OC-16/99 sobre el Derecho a la Información sobre la Asistencia Consular en el Marco de las Garantías del Debido Proceso Legal (1999): Corte Interamericana de Derechos Humanos, 1 de octubre de 1999. Serie A No 16.

Opinión Consultiva OC-18/03 sobre Condición Jurídica y Derechos de los Migrantes Indocumentados (2003): Corte Interamericana de Derechos Humanos, 17 de septiembre de 2003. Serie A No 18.

Caso Ricardo Canese vs. Paraguay (2004): Corte Interamericana de Derechos Humanos, 31 de agosto de 2004. Serie C N 111.

Caso Almonacid Arellano y otros vs. Chile (2006): Corte Interamericana de Derechos Humanos, 26 de septiembre de 2006. Serie C N 154.

Caso La Cantuta vs. Perú (2006): Corte Interamericana de Derechos Humanos, 29 de noviembre de 2006. Serie C N 162.

Caso Zambrano Vélez y otros vs. Ecuador (2007): Corte Interamericana de Derechos Humanos, 4 de julio de 2007. Serie C N 166.

Requerimiento de inaplicabilidad por inconstitucionalidad de Banco de Crédito e Inversiones $S$. A. respecto del artículo 12, inciso final, del Código del Trabajo, en la causa Rol $N^{\circ}$ 2556-2008, del Primer Juzgado de Letras del Trabajo de La Serena, caratulada "Banco BCl con Inspección Provincial del Trabajo de Coquimbo" (2009): Tribunal Constitucional, 28 de abril de 2009, rol n 1252-2008.

Caso Vélez Loor vs. Panamá (2010): Corte Interamericana de Derechos 
Humanos, 23 de noviembre de 2010. Serie C No 218.

Requerimiento de inaplicabilidad por inconstitucionalidad de Leonardo del Tránsito Mazuela Montenegro, respecto de los artículos 364, 37 2,373,374,375,376,377,378,379,380,381,382,383,385,386 y 387 del Código Procesal Penal, en rit 22 - 2009 y ruc 0800077921 - 1 del Tribunal Oral en lo Penal de los Andes (2010): Tribunal Constitucional, 5 de agosto de 2010, rol $n^{\circ} 1432-2009$.

Murias con Ministerio del Interior y Seguridad Pública (2011): CS, 3 de agosto de 2011 (reclamación especial del artículo 89 del Decreto Ley 1094 de 1975), rol n 6398-2011.

Caso Nadege y otros vs. República Dominicana (2012): Corte Interamericana de Derechos Humanos, 24 de octubre 2012. Serie C No 251.

Barahona y otras con Jefatura de Extranjería y Policía Internacional de Investigaciones de Chile, Departamento de Extranjería y Migración del Ministerio del Interior (2013): CAS, 22 de abril de 2013 (amparo), rol $\mathrm{n}^{\circ}$ 550-2013.

Barahona y otras con Jefatura de Extranjería y Policía Internacional de Investigaciones de Chile, Departamento de Extranjería y Migración del Ministerio del Interior (2013): CS, 7 de mayo de 2013 (apelación amparo), rol n²837-2013.

Caso Familia Pacheco Tineo vs. Bolivia (2013): Corte Interamericana de Derechos Humanos, 25 de noviembre de 2013. Serie C No272.

Caso Gelman vs. Uruguay (2013): Corte Interamericana de Derechos Humanos, Supervisión de Cumplimiento de Sentencia, 20 de marzo de 2013.

Díaz con Departamento de Extranjería y Migración del Ministerio del Interior y Seguridad Pública (2013): CAS, 21 de enero de 2013 (amparo), rol n 19-2013.

Díaz con Departamento de Extranjería y Migración del Ministerio del Interior y Seguridad Pública (2013): CS, 4 de febrero de 2013 (apelación amparo), rol n 805-2013.

Marín y otros con Ministerio del Interior y Seguridad Pública y otros (2013):

CAS, 9 de marzo de 2013 (amparo), rol n 351-2013.

Requerimiento de inaplicabilidad por inconstitucionalidad presentado por 
el ciudadano haitiano Daniel Alerte, respecto de los artículos 13, 64 $N^{\circ} 2$ y 67 del Decreto Ley $N^{\circ} 1.094$, de 1975, que establece normas sobre extranjeros en Chile, en relación a los autos sobre recurso de protección, de que conoce la CAS, bajo el Rol N²1.751-2012 (2013): Tribunal Constitucional, 4 de julio de 2013 (requerimiento de inaplicabilidad por inconstitucionalidad), rol $\mathrm{n}^{\circ} 2273-12$.

Caso de personas dominicanas y haitianas expulsadas vs. República Dominicana (2014): Corte Interamericana de Derechos Humanos, 28 de agosto de 2014. Serie C No282.

Castro con Intendencia Regional de Arica y Parinacota y otro (2014): CS, 19 de febrero 2014 (apelación de amparo, voto disidente de los ministros Cisternas y Chevesich), rol n 3999-2014.

Cabrera con Intendencia Regional de Atacama (2015): Corte de Apelaciones de Copiapó, 20 de octubre de 2015 (amparo), rol N²90-2015. Fernández con Ministerio del Interior y Seguridad Pública (2015): CAS, 27 de julio de 2015 (amparo), rol n 1209-2015.

Fernández con Ministerio del Interior y Seguridad Pública (2015): CS, 6 de agosto de 2015 (apelación de amparo), rol n 10035-2015.

Sosa contra Intendencia de la Región Antofagasta (2015): CS, 23 de febrero de 2015 (apelación de amparo), rol n³073-2015.

Ortiz con Intendencia de la Región de Arica y Parinacota (2016): CS, 1 de marzo de 2016 (apelación de amparo), rol n 16034-2016.

Terrero contra Intendencia Regional Metropolitana (2017): CAS, 7 de diciembre de 2017 (amparo), rol n 3137-2017,

Utria y Utria contra Ministerio del Interior y Seguridad Pública (2018): CAS, 1 de marzo de 2018 (amparo), rol n² 262-2018.

Utria y Utria contra Ministerio del Interior y Seguridad Pública (2018): CS,

12 de marzo de 2018 (apelación de amparo), rol n³743-2018. 